\title{
ANTI-OPPRESSIVE PRACTICE IN HARM REDUCTION
}

by

Travis Cross, BSW, University of Victoria, 2017

\author{
An MRP \\ presented to Ryerson University \\ in partial fulfillment of the \\ requirements for the degree of \\ Master of Social Work \\ in the Program of \\ Social Work
}

Toronto, Ontario, Canada, 2020

(C) Travis Cross 2020 


\section{AUTHOR'S DECLARATION FOR ELECTRONIC SUBMISSION OF A MRP}

I hereby declare that I am the sole author of this MRP. This is a true copy of the MRP, including any required final revisions.

I authorize Ryerson University to lend this MRP to other institutions or individuals for the purpose of scholarly research

I further authorize Ryerson University to reproduce this MRP by photocopying or by other means, in total or in part, at the request of other institutions or individuals for the purpose of scholarly research.

I understand that my MRP may be made electronically available to the public. 


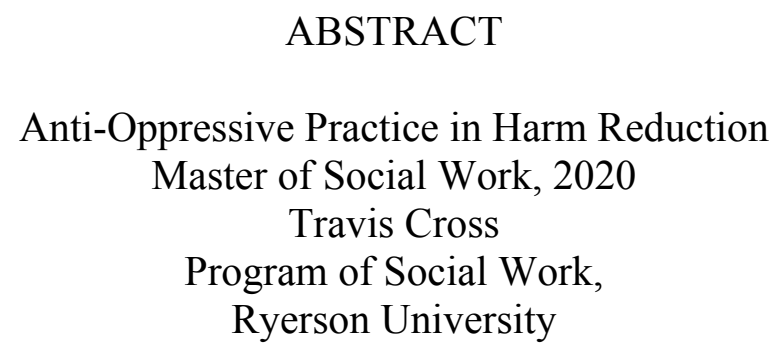

This study interrogates the current neoliberal harm reduction model and examines antioppressive practice within harm reduction through the following research question: how do harm reduction workers in Toronto address structural processes of oppression through their work? Three harm reduction workers participated in one-on-one, semi-structured interviews for this study, and were asked to discuss their understandings and experiences with harm reduction and anti-oppression. Through a phenomenological analysis of participant responses, three themes were developed: participants conceptualize harm reduction beyond personal substance use; facilitate peer engagement and mobilization; and challenge incarceration, policing, and surveillance. These findings indicate that research participants engage in multiple forms of politicized practice that collectively challenge the neoliberal tenet of personal responsibility within harm reduction, as well as the role of the criminal justice system in the lives of people who use drugs. This study concludes with implications for social work practice and research. 


\section{ACKNOWLEDGEMENTS}

This major research paper was written during the most challenging year of my life, and it would not have been possible to complete this project without the support of many people.

I first wish to acknowledge my chosen family, who have provided so much love and encouragement throughout this process. To Leanne Edwards (Mrs. Lindsay), thank you for always believing in me, thank you for your patience, and thank you for your incredible generosity. To Juls Budau, thank you for listening, for always validating my feelings, for your hospital visits, and for being present in my life when many people were not. To Lindsay Mack, your friendship is so important to me, and I am so grateful that you invited me into your home. To Marvell Eagleson, thank you for lending me your apartment and a desk on which to write this MRP!

I would also like to acknowledge some dear friends who have been with me every step of this journey. To Beshele Caron, thank you so much for your reassurance and peer support as we navigated our MSWs together. To Mak McKinley, your enthusiasm for my research gave me confidence when I was feeling low; I appreciate your friendship so much.

I wish to acknowledge some of the professors and staff at Ryerson University. To my supervisor, Dr. Dawn Onishenko, I am grateful for your guidance, your patience, your kindness, and your faith in my academic abilities; my research is stronger because of your support. To Dr. Purnima George, thank you for teaching me to love critical qualitative research! To my second reader, Dr. Jennifer Poole, thank you for being supportive and encouraging when I was fearful of returning to this project. To Milene Ferreira, graduate program administrator, your assistance in facilitating my successful completion of this research project was invaluable. Finally, to Reece Steinberg at the Ryerson University Library and Archives, your research assistance was always 
prompt and extremely helpful, even when it veered off-topic; your friendship means so much to me. 


\section{DEDICATION}

This MRP is dedicated to Silvia Knittel. Thank you for always being proud of me. 


\section{TABLE OF CONTENTS}

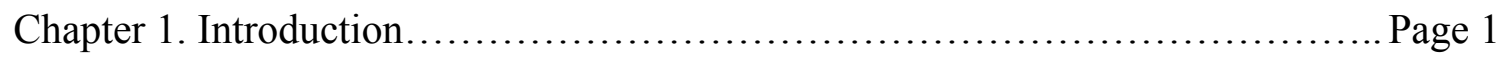

Chapter 2. Theoretical Framework...................................... Page 4

Neoliberalism..................................................Page 4

Anti-Oppressive Social Work Practice................................. Page 7

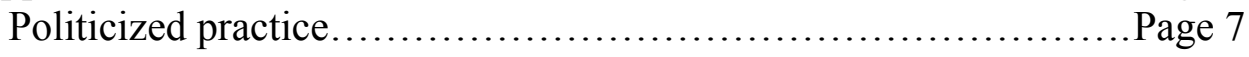

Peer involvement.......................................... Page 7

AOP and the criminal justice system..........................Page 8

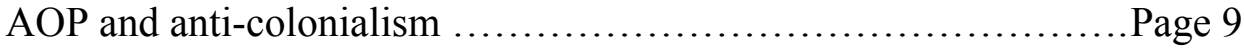

Applying AOP to harm reduction............................... Page 10

Chapter 3. Literature Review.......................................... 11

Defining Harm Reduction: Meanings, Values, and Debates................ Page 11

A public health and human rights approach...................... Page 12

A peer-led political and social justice movement...................Page 13

A depoliticized response to substance use..........................Page 14

Summary ......................................................... 15

The Neoliberal Harm Reduction Model............................... Page 15

Harm reduction and social control.............................Page 15

Harm reduction and personal responsibility......................... Page 17

Reclaiming personal responsibility for social justice............... Page 18

Summary............................................... Page 20

Structural Approaches to Harm Reduction............................ Page 20

Harm reduction and anti-colonialism...........................Page 20

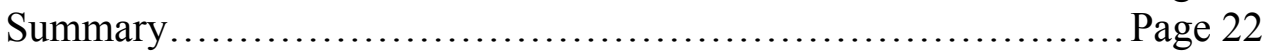

Conclusion...................................................... Page 22

Chapter 4. Methodology............................................. Page 25

Recruitment..................................................Page 26

Data Collection................................................... Page 27

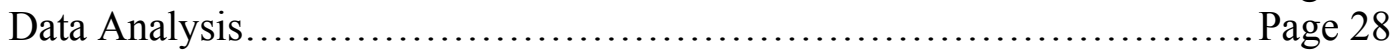

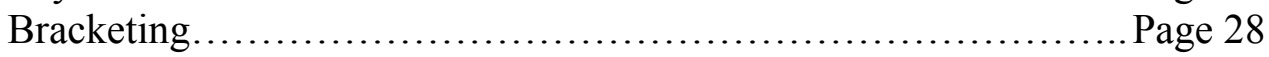

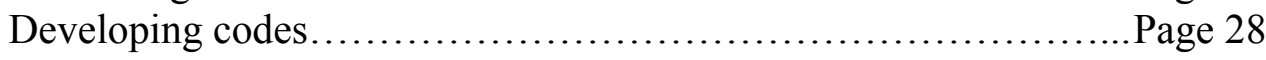

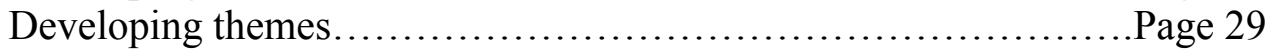

Critically Reflecting on the Absence of Anti-Colonialism in the Findings

of this MRP..................................................... Page 30

Ethical Considerations.............................................. Page 31

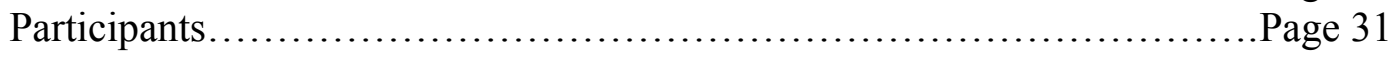

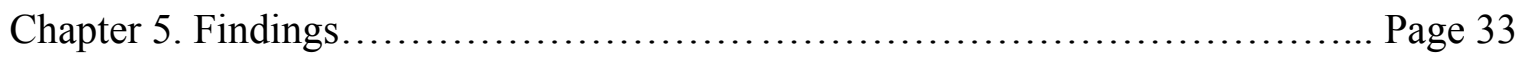


Theme One: Conceptualizing Harm Reduction Beyond Personal

Substance Use .................................................. Page 33

Theme Two: Peer Engagement and Mobilization...................... Page 35

Theme Three: Challenging Incarceration, Policing, and Surveillance........ Page 38

Conclusion.................................................. Page 43

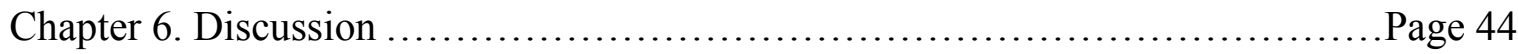

The Meaning of Harm Reduction................................... Page 44

Neoliberalism.................................................... Page 46

Harm reduction and social control.............................Page 46

Harm reduction and personal responsibility....................... Page 47

Peer outreach and personal responsibility................. Page 49

Anti-Oppressive Practice..........................................Page 49

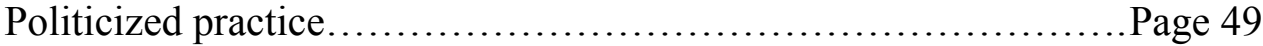

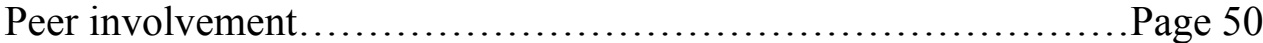

AOP and the criminal justice system..........................Page 51

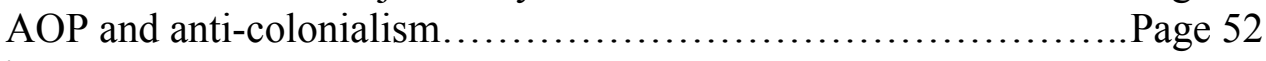

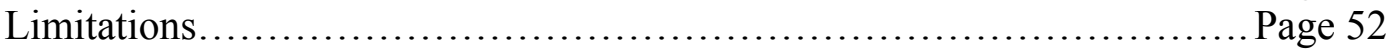

Chapter 7. Conclusion............................................... Page 54

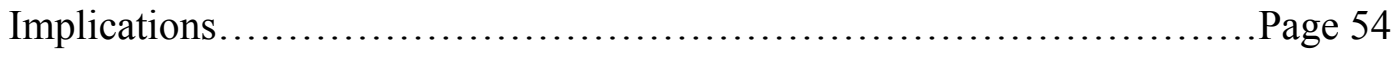

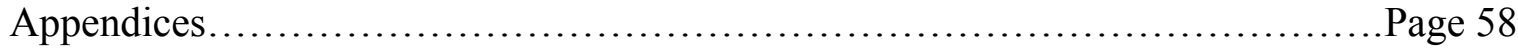

References........................................................... 68 


\section{LIST OF APPENDICES}

Appendix A. Recruitment Poster................................. Page 58

Appendix B. Recruitment Email Script.............................. Page 59

Appendix C. Recruitment Handbill..................................Page 60

Appendix D. Interview Guide..................................... Page 61

Appendix E. Ethics Approval ....................................Page 63

Appendix F. Consent Form..................................... Page 64 


\section{CHAPTER 1. INTRODUCTION}

This major research paper (MRP) seeks to better understand anti-oppressive practice within the field of harm reduction by exploring the following research question: how do individuals working within harm reduction organizations in Toronto address structural processes of oppression through their work? According to Hyshka et al. (2019), "a harm reduction approach includes policies and programs that aim to help people who use drugs (PWUD) be safer and healthier without requiring abstinence or reduction in use" (p. 2). Harm reduction in Canada emerged in the 1980s in response to the AIDS crisis, as a politicized movement that not only provided supplies to reduce the individual risk of seroconversion, but also challenged the socio-political and economic marginalization of people living with HIV/AIDS (Roe, 2005). Roe, as well as Smith (2012a), contend that harm reduction has since evolved into a biomedical approach focused on altering the individual risk behaviours of substance users. By focusing on individual behaviours, the current harm reduction model conceptualizes risks and harms as resulting mainly from individual choice, and does not necessarily take into account political and socio-economic factors that can increase harm for people who use drugs (Miller, 2001; Moore \& Fraser, 2006; Rhodes, 2009; Roe, 2005).

Several authors advocate for structural approaches to harm reduction (Gupta, Parkhurst, Ogden, Aggleton, \& Mahal, 2008; Pauly, 2008; Souleymanov \& Allman, 2016). Structural approaches are harm reduction initiatives that not only support people in changing risk behaviours, but also address the root social, political, and economic factors that influence those behaviours (Gupta et al., 2008). By highlighting strategies undertaken by harm reduction workers to address structural oppressions, this MRP contributes to this discussion. By structural oppressions, I am referring to social processes that marginalize individuals based on their 
affiliations with specific groups (Baines, 2017a). Oppressions are structural because they are not the result of the irrational thinking of individuals, but rather are rooted in the norms and institutions of society (Mullaly, 2007; Young, 1990). Scholars have documented how processes of oppression such as colonialism (First Nations Health Authority, FNHA, n.d.; Goodman et al., 2017), anti-Black racism (Cooper et al., 2016), patriarchy (Bourgois, Prince, \& Moss, 2004; Boyd et al., 2018), and poverty (McLean, 2016) can intersect with substance use and increase harm for people who use drugs.

My research is premised on the following arguments, which will be developed more fully in the theoretical framework and literature review chapters of this MRP: firstly, a purely individualized approach to harm reduction reflects neoliberal values (Moore \& Fraser, 2006); secondly, individualized approaches may not fully meet the needs of service users (Dodds, 2002); thirdly, this model of harm reduction may obscure structural processes of marginalization that can generate harm for individuals and groups (Pauly, 2008); and fourthly, individuals may be pathologized under this model, when they are deemed to engage in irresponsible substance use (Pauly, McCall, Browne, Parker, \& Mollison, 2015). However, my critiques of the current harm reduction model must not be interpreted as a rejection of harm reduction itself. I write this MRP in the midst of an opioid poisoning epidemic that killed more than 11500 people in Canada between 2016 and 2018 (Government of Canada, 2019). Harm reduction programs such as supervised injection sites and take home naloxone programs are saving lives during this crisis (Irvine et al., 2019; Leece et al., 2016), and are therefore indispensable.

My understanding of this research topic is informed by my positionalities as a queer person, as someone living with HIV, and as a harm reduction worker. As a queer, harm reduction helps my community thrive in the face of stigma and homophobia. I view harm reduction as it is 
practiced within my community as a deeply political form of mutual aid and collective care, as well as a creative strategy to resist heteronormativity. However, as someone living with HIV, I also experience the pathology of the neoliberal harm reduction model. Whereas I understand my poz status to be resultant of societal homophobia and structural stigma within the health care system, from the perspective of neoliberal harm reduction my serostatus is attributed to irresponsible sexual and drug-using behaviours; I reject this analysis. As a harm reduction worker, I have also witnessed the violence that is sustained by harm reduction policies that ignore the harms generated by colonialism, patriarchy, homophobia, transphobia, poverty, and criminalization; I strongly believe that we must expand our understanding of harm reduction to address these structural forces in conjunction with current biomedical approaches.

This MRP is comprised of seven chapters. In chapter two I outline the theoretical framework of this research, consisting of neoliberalism and anti-oppressive social work practice. In chapter three I conduct a literature review of scholarship on the meaning of harm reduction, the neoliberal harm reduction model, and structural approaches to harm reduction. In chapter four I discuss my research methodology, interpretive phenomenology, and detail my recruitment strategy, data collection methods, procedure for data analysis, ethical considerations, and methodological shortcomings. I present my research findings in chapter five, and in chapter six I relate these findings to the literature and theoretical framework, and then discuss the limitations of this research. I conclude in chapter seven with implications for social work practice. 


\section{CHAPTER 2. THEORETICAL FRAMEWORK}

This chapter examines the theories guiding this research project: neoliberalism and antioppressive social work practice (AOP). I utilize neoliberalism as a lens through which to interpret the functioning of the current harm reduction model. I make use of AOP as a tool to critique the neoliberal harm reduction model, and as a framework for conceptualizing and evaluating structural approaches to harm reduction.

\section{Neoliberalism}

Neoliberalism can be understood as the restructuring of all aspects of society in order to facilitate capitalist expansion while minimizing welfare state spending (Ayo, 2012). From a neoliberal perspective, social issues are most effectively addressed through "market-like mechanisms" (Wacquant, 2009, p. 307); therefore, the application of market principles to all aspects of life, including human behaviour, is a fundamental tenet of neoliberal thought (Foucault, 2008; Lemke, 2001; Wacquant, 2009).

Although capitalist accumulation is a primary goal of neoliberal restructuring (Duggan, 2003), an additional effect of neoliberalism is to produce, manage, and reinforce hierarchical social relations (Butler \& Althanasiou, 2013; Duggan, 2003). The neoliberal restructuring of the economy and society results in increasing employment insecurity for many, and these economic effects are compounded by ongoing cuts to health and social services that further increase precarity (Butler \& Althanasiou, 2013). These economic and social processes allocate power and privilege to certain groups, while reinforcing marginalization for others (Butler \& Althanasiou, 2013). Through neoliberal restructuring, privilege and precarity are allocated largely in relation to norms of race, gender, sexuality, class, and ability (Butler \& Althanasiou, 2013; Duggan, 
2003). That is to say, neoliberalism functions to reinscribe white supremacy, heteropatriarchy, capitalism, ableism, and other structures of domination.

The social and economic inequities exacerbated by neoliberal restructuring are addressed by what Wacquant (2009) refers to as "an expansive, intrusive, and proactive penal apparatus" (p. 307). In other words, the criminal justice system is utilized within neoliberalism to surveil and contain marginalized groups. This is exemplified by the criminalization of substance use and the ongoing war on drug users, which disproportionately targets Indigenous communities and communities of colour (Gordon, 2006; Khenti, 2014; Marshall, 2015). Furthermore, criminalization constructs substance use solely as a matter of personal choice and irresponsible behaviour (Marshall, 2015), thereby obscuring the systemic inequities that can influence drug consumption (Dollar, 2018; Marshall, 2015). It is important to recognize that within the context of neoliberalism, social services often function in ways that surveil and regulate marginalized groups (Pollack \& Rossiter, 2010; Pon, Gosine, \& Phillips, 2011; Wacquant, 2001), therefore augmenting the work of the criminal justice system.

The concept of personal responsibility is a major tenet of neoliberal thought (Wacquant, 2009). From a neoliberal perspective, individuals are understood to be prudent economic actors, and therefore have a moral responsibility to make the best personal choices possible based on a rational cost-benefit analysis of any potential action (Lemke, 2001; Pollack \& Rossiter, 2010). Individuals are encouraged through a variety of means to take responsibility for their own selfcare, which constitutes a form of self-government and relieves the state of much of its obligation to address social inequities (Lemke, 2001). Furthermore, as the neoliberal subject is understood to be a rational decision-maker, social issues such as poverty, substance use, and homelessness are perceived to be the result of poor personal choices (Ayo, 2012; Pollack \& Rossiter, 2010). 
This perspective obscures the role of historical and present-day structural factors that contribute to health and social inequities (Ayo, 2012; Duggan, 2003).

The dominant model of harm reduction understands exposure to risk and harm to be primarily the result of personal decision-making, and therefore harm reduction policies and programs are often designed to alter individual behaviours (Gupta et al., 2008; Moore \& Fraser, 2006; Rhodes, 2009; Souleymanov \& Allman, 2016). In this way, people who use substances are tasked with the responsibility to protect their own health (Krüsi, McNeil, Moore, \& Small, 2017), while socio-political and economic factors that can also increase risk and generate harm are left unchallenged (Miller, 2001; Moore \& Fraser, 2006; Rhodes, 2009; Souleymanov \& Allman, 2016). The dominant harm reduction model can therefore be understood to reflect neoliberal values, as it focuses on the personal responsibility of substance users to change their behaviours, while mainly ignoring structural determinants of harm. Furthermore, when the historical and structural contexts that influence personal behaviour and choice are ignored, harm reduction workers may inadvertently pathologize individuals who are deemed to engage in irrational or irresponsible substance use (Foth, O-Byrne, \& Holmes, 2016; Krüsi et al., 2017; Moore \& Fraser, 2006; Pauly et al., 2015; Rhodes, 2009; Souleymanov \& Allman, 2016).

\section{Anti-Oppressive Social Work Practice}

AOP is a politicized approach to social work that rejects the neutral stance traditionally espoused by helping professions (Baines, 2017a), seeking instead to disrupt oppressive power relations and facilitate social change (Baines, 2017a; Larson, 2008; Pollack, 2004). Rather than

focusing on a singular form of oppression, AOP takes a non-hierarchical, intersectional approach that recognizes the multiplicity and interlocking nature of oppressions (Moosa-Mitha, 2015). 
Politicized practice. From an anti-oppression perspective, problems experienced by service users are not necessarily the result of individual choices, and are understood to be connected to larger historical, social, political, and economic processes that generate and maintain inequity (Baines, 2017a). When social workers practice from this perspective, client behaviours deemed to be pathological may alternatively be understood as acts of resistance against the oppressions they experience (Brown, 2017; Burstow, 2003; Reynolds, 2016). Furthermore, while it is necessary to support service users in meeting their basic needs (Strier \& Binyamin, 2010), AOP is also an action-oriented approach (Baines, 2017a) that calls for workers and agencies to engage in political actions at both the micro and macro-levels to support systemic change (Baines, 2017a; Barnoff, Abdillahi, \& Jordan, 2017; Karabanow, 2004; Ross, 2017; Strier \& Binyamin, 2010). However, Ross contends that macro-level actions have become more difficult to execute within the current neoliberal environment, and advocates that we adopt a "big tent approach" (p. 314) that equally values the political potential of micro-level initiatives.

Peer involvement. According to Dumbrill and Yee (2019), oppression can be amplified for service users when their knowledge is marginalized; therefore, AOP scholars emphasize the meaningful incorporation of service users' knowledge within social service provision (Barnoff, Abdillahi, \& Jordan, 2017; Dumbrill \& Yee, 2019; Karabanow, 2004; Larson, 2008; Pollack, 2004; Strier \& Binyamin, 2010). It is imperative that such involvement is not tokenistic (Karabanow, 2004); people with lived experience must exercise meaningful decision-making power, and should occupy managerial and policy-making positions, as well as positions on boards of directors (Barnoff, Abdillahi, \& Jordan, 2017; Strier \& Binyamin, 2010). It is also important that AOP organizations engage in community-led evaluation processes, to ensure that 
agencies remain accountable to the communities they serve (Barnoff, Abdillahi, \& Jordan, 2017; Strier \& Binyamin, 2010). However, Dumbrill and Yee point out that social service agencies often fall short in achieving the ideal of service user involvement. In this MRP I make use of the term "peer" when referring to people with lived experience, as this term is commonly used within the harm reduction field (Canadian AIDS Society, 2015; Greer et al., 2016).

AOP and the criminal justice system. As discussed above, the economic and social inequities exacerbated by neoliberal restructuring are managed in part through an expanded criminal justice system (Wacquant, 2009). However, after consulting the AOP literature, I have found that only a limited number of texts contain an analysis of the criminal justice system. Dumbrill and Yee (2019) identify policing as a form of coercive power that protects powerful groups and maintains the dominant social order; however, they do not discuss the implications of this power for social work or social service users. Willison and O'Brien (2017) call on social workers to take up criminal justice system reform as "an urgent social justice issue for our field" (p. 38); these authors argue for an anti-oppressive approach to justice that includes the reallocation of public funds to support health and social services, increased support for families, as well as community-based restorative justice programs to replace mass incarceration. O'Brien and Ortega (2015) also suggest that social workers support decarceration and prison abolition. These authors contend that racism and oppression are "inherent to the prison system" (p. 143), and advocate for an alternative model of community accountability to address harm. Goldingay (2016) and Pollack (2004) both observe that the values of anti-oppressive social work conflict with the punitive goals of the carceral system, yet these authors do not call for decarceration, prison abolition, or critique the purpose of criminal justice system. Instead, both Goldingay and 
Pollack suggest only that social workers attempt to promote more equitable power relations inside the prison system.

AOP and anti-colonialism. The social work profession has been, and continues to be, complicit in maintaining colonial violence (Baskin, 2016; Lee \& Ferrer, 2014; Sinclair, 2004). Some scholars critique AOP frameworks for not adequately addressing processes of colonialism and racism that undergird Canadian society and social work practice (Barnoff \& Moffatt, 2007; Baskin \& Davey, 2017; Dumbrill \& Yee, 2019; Yee \& Wagner, 2013). According to Dumbrill and Yee, "the potential for anti-oppression to decolonize has not been realized" (p. 189). Baskin and Davey argue that, because AOP focuses on all oppressions simultaneously, the impacts of colonialism and white supremacy can be disregarded.

In order to address AOP's limitations concerning colonialism and white supremacy, Yee and Wagner (2013) argue that it is necessary to center anti-colonialism and anti-racism within our work. To this end, several scholars provide specific recommendations for anti-oppressive practice with Indigenous communities (Sinclair, 2004; Thomas \& Green, 2007; Freeman, 2017). This includes the necessity for AOP agencies to respectfully incorporate Indigenous knowledges and healing practices into their service provision for Indigenous clients (Freeman, 2017). However, in doing so, it is also crucial that non-Indigenous service providers learn to defer to Indigenous Elders and other knowledge holders (Freeman, 2017). Non-Indigenous social workers must also critically reflect on our own knowledges, values, beliefs, and assumptions about Indigenous peoples, in order to disrupt colonial power relations (Thomas \& Green, 2007). Furthermore, it is critical for settler social workers to increase our understanding of historical and ongoing processes of colonization, and the role these processes play in contemporary health and 
social issues experienced within Indigenous communities (Freeman, 2017; Sinclair, 2004; Thomas \& Green, 2007).

Applying AOP to harm reduction. I have selected AOP as a theory within this MRP because I believe an anti-oppressive analysis can be useful to critique neoliberal harm reduction and conceptualize alternatives to the current model. Whereas neoliberal harm reduction concentrates on individual substance-using behaviours, an AOP perspective can expand our focus to include the historical, political, and social dimensions of substance use and risk. An AOP analysis can also be useful in centering political action and the experiential knowledge of people who use drugs in our harm reduction work. 


\section{CHAPTER 3. LITERATURE REVIEW}

This literature review is comprised of four sections. I begin by exploring the values and knowledge claims of harm reduction as philosophy, social movement, and public health policy. I then continue the examination of neoliberalism started in the previous chapter, by focusing on the ways that neoliberal tenets of personal responsibility and social control influence the current harm reduction model. In the third section of this literature review I survey structural approaches to harm reduction, paying particular attention to anti-colonial approaches. I conclude this chapter by identifying gaps in the literature, and situate my own research in relation to the current scholarship.

\section{Defining Harm Reduction: Meanings, Values, and Debates}

A universally agreed upon definition of harm reduction does not exist (Harm Reduction International, HRI, 2019; Klein, 2015). According to Klein, the definition of harm reduction is contested because harm reduction performs varying roles; these include grassroots social movement, international human rights movement, and state response to substance use (Klein, 2015). Despite the lack of consensus on the definition of harm reduction, scholars and activists have nonetheless identified key features of a harm reduction approach to working with people who use drugs; these include the promotion of public health and human rights (HRI, 2019; Stimson, 2007), the meaningful involvement of people who use drugs (Friedman et al., 2007; HRI, 2019), and a commitment to political change and social justice (HRI, 2019). However, other scholars argue that a distinguishing feature of contemporary harm reduction is that it has become depoliticized through its incorporation into mainstream health care (Roe, 2005; Smith, 2012a). 
A public health and human rights approach. Canadian substance use policy has historically focused on the criminalization of people who use drugs, as well as abstinence-only treatment (Csiernik, Rowe, \& Watkin, 2017). In contrast, harm reduction is both a public health and human rights-based approach to working with people who use drugs (Stimson, 2007; HRI, 2019). Referring to the public health aspects of harm reduction, Stimson writes that harm reduction is a pragmatic and evidence-based approach that targets specific health-related harms associated with drug use. Regarding human rights, harm reduction supports the right to life and security, health protection, medical treatment, and protection from state violence (Stimson, 2007).

While harm reduction supports both the health and human rights of people who use drugs, Jiao (2019) argues that these dual orientations are undergirded by conflicting epistemological and ontological assumptions. Jiao refers to public health initiatives, such as supervised injection sites and opioid agonist therapy, as a "technical approach" (p. 2) to harm reduction. The author writes that this approach privileges biomedical knowledge as a singular truth, and therefore reflects a post-positivist knowledge paradigm. Furthermore, Jiao argues that within this approach risk and harm are defined by medical experts, and are understood to originate within the epidemiology of substance use. Jiao refers to rights-oriented initiatives, such as housing first programs, as a "social approach" (p. 2) to harm reduction. Jiao writes that the social approach privileges the experiential and contextual knowledge of people who use drugs, and therefore reflects constructivist and critical knowledge paradigms. According to Jiao, within the social approach risk and harm are defined by people who use drugs, and are understood to originate mainly within the broader social and political environment. Jiao contends that the knowledge claims of technical harm reduction are privileged over those of the social approach, 
and further argues that we must "level the existing hierarchy" (p. 4) between medical and experiential knowledge, in order to best support people who use drugs.

A Peer-led political and social justice movement. HRI (2019) identifies a commitment to social justice as a fundamental principle of harm reduction. According to HRI, the commitment to social justice includes ensuring that no one is discriminated against or denied health and social services based on their substance use, race, gender, gender identity, sexual orientation, choice of work, or economic status. Furthermore, HRI maintains that people who use drugs must be meaningfully involved in the design, implementation, and evaluation of harm reduction policies and programs.

Harm reduction's orientation as a peer-led political and social justice movement is demonstrated globally by drug user unions and direct action groups (Friedman et al., 2007). In Canada, The Vancouver Area Network of Drug Users (VANDU) serves as a current example of peer organizing and political action. VANDU was established in response to government's failure to adequately address dual overdose and HIV/AIDS epidemics in Vancouver's Downtown Eastside (DTES) neighbourhood (Jozaghi, 2014; Kerr et al., 2006). VANDU has organized numerous direct action protests to draw political attention to drug overdose and HIV/AIDS (Kerr et al., 2006). Additionally, the organization initiated both an unsanctioned needle exchange (Kerr et al., 2006) and an unsanctioned supervised injection site (Kerr, Oleson, Tyndall, \& Wood, 2005) to meet the health care needs of injection drug users. VANDU has successfully reduced overdose incidents and risky injecting behaviour in the DTES, reduced incidents of discrimination from health officials and police, and increased peer involvement in civic affairs (Jozaghi, 2014). In Toronto, peers and other harm reduction activists have formed the Toronto Harm Reduction Alliance. This advocacy group opened the city's first overdose 
prevention site in response to government inaction during the present opioid poisoning epidemic (CMAJ, 2018).

A depoliticized response to substance use. Despite the examples of peer organizing described above, some scholars argue that harm reduction has become depoliticized through its incorporation into mainstream health care (Roe, 2005; Smith, 2012a). Depoliticized harm reduction, as defined by Smith, refers to "the systemic exclusion of a structural, politicaleconomic critique in the etiology of addiction" (p. 209). According to Roe, policy makers are critical of activism-based harm reduction; therefore, in order for harm reduction to gain governmental support, demands for social justice and political change within the harm reduction movement have been minimized. Furthermore, policy makers privilege biomedical knowledge over the experiential knowledge of people who use drugs, resulting in medical experts exerting more control than peers over the development of harm reduction initiatives (Roe, 2005). For these reasons, Roe argues that harm reduction has evolved into a "conservative movement" ( $p$. 248).

The argument that harm reduction has become depoliticized may be supported by Hyshka et al.'s (2017) analysis of 102 Canadian harm reduction policy documents current to the end of 2015. According to Hyshka et al., core principles of harm reduction, such as peer involvement in policy development and implementation, were poorly defined or absent in almost all documents. Hyshka et al. further note that most documents failed to address the specific harm reduction needs of women, youth, Indigenous peoples, and 2SLGBTQ+ people. Hyshka et al. posit that by neglecting to affirm harm reduction's core principles within these documents, policy-makers may be signaling a lack of support for some of the fundamental yet politically controversial tenets of harm reduction. Federal and provincial harm reduction policy documents current to 
2019 (Government of Canada, 2018; Ministry of Health and Long-Term Care, 2018) similarly lack reference to principles of peer involvement and social change.

Summary. In contrast to traditional punitive and abstinence-based responses to substance use, harm reduction can be understood as a dual public health and human rights approach to working with people who use drugs. However, these dual orientations are supported by conflicting epistemological and ontological assumptions. Harm reduction can also be understood as a user-led political and social justice movement, as demonstrated by drug user organizing. However, harm reduction may have also become depoliticized through its incorporation into public health. The absence of politically contentious principles from current harm reduction policy documents, such as a commitment to social justice and the meaningful involvement of peers, may provide evidence of this depoliticization.

\section{The Neoliberal Harm Reduction Model}

In this section of the literature review, I analyze the influence of neoliberal principles of social control and personal responsibility within the current harm reduction model. I then examine scholarship highlighting ways in which the tenet of personal responsibility has been reclaimed to support social justice and anti-oppression.

Harm reduction and social control. As discussed in the theoretical framework chapter of this MRP, neoliberal ideology opposes increased social welfare spending to address inequities, and simultaneously promotes an expanded "penal apparatus" (Wacquant, 2009, p. 307) of surveillance, control, and discipline to contain marginalized groups. Supervised injection sites (SIS) can facilitate these functions in the lives of people who use drugs. Fischer, Turnbull, Poland, and Hayden (2004) argue that SIS function as sites of governmentality within the neoliberal city, through which drug-using subjects are disciplined to internalize messages of self- 
care and "healthy self-transformation" (p. 363), in order to become responsible and healthconscious citizens. According to these authors, this is accomplished primarily through noncoercive means, such as the collection of data related to injection drug use history, health problems, and incidents of needle sharing. Fischer et al. suggest that this form of "government at a distance" (p. 363) can actually justify and perhaps reinforce the punitive treatment of people who use drugs. This is because individuals who are unable or unwilling to modify their behaviours in accordance with the expectations of public health are perceived to be a threat to order and safety, and are therefore dealt with more intensively by the criminal justice system (Fischer et al., 2004).

Elliot (2014) investigated how disciplinary processes operate at Insite, Canada's first legally sanctioned SIS located in Vancouver's DTES. The author writes that by removing substance users from the street, Insite functions to contain the urban poor of this rapidly gentrifying neighbourhood. Elliot further notes that DTES residents have been constructed by media reports and academic publications as chaotic and in need of management, and argues that such constructions are used to justify heightened security and surveillance practices in and around Insite.

Increased police surveillance may have a negative impact on the usage of SIS, as suggested by Bardwell, Strike, Altenberg, Barnaby, and Kerr's (2019) study of policing in the vicinity of two SIS in Toronto. The authors observed that one of the SIS studied is located in a neighbourhood with a large police presence; the authors attribute this to the area containing a greater concentration of health and social services for people who use drugs, as well as the presence of a visible street-based drug scene. Many service users at this SIS described the heightened police presence as a barrier to accessing the site, and reported instances when they 
would avoid the site altogether, in order to avoid police interactions (Bardwell et al., 2019). In contrast, the second SIS examined by Bardwell et al. is located in a "family-oriented" (p. 6) neighbourhood with a less visible street-based drug scene, and the authors observed an "almost non-existent" (p. 6) police presence in the vicinity of the second SIS. Service users at this location did not report a need to avoid the SIS, describing instead feelings of safety and immunity from arrest at this location (Bardwell et al., 2019). Bardwell et al.'s study suggests that neighbourhood policing and surveillance practices can negatively impact peoples' ability to access SIS in Toronto.

Harm reduction and personal responsibility. The neoliberal principle of personal responsibility is evident within public health messaging to promote safer using practices. In an analysis of Australian Hepatitis C (HCV) prevention and safer injecting materials, Fraser (2004) found that the majority of documents portrayed people who inject drugs as individually responsible for HCV transmission, without acknowledging political and socio-economic factors that can influence injecting behaviours. Dodds (2002) and Thomann (2018) have conducted similar analyses of HIV prevention materials, and both concluded that messages of individual responsibility are also prioritized over structural approaches within HIV prevention campaigns.

McLean's (2015) examination of a harm reduction agency in New York, NY shows how a singular focus on personal responsibility may contribute to the pathologization of people who use drugs. The author notes that the agency under study focused almost exclusively on clients' responsibility to alter personal behaviours. McLean observed that clients who were unable or unwilling to modify their substance-using behaviours were deemed by some staff to be either severely addicted or personally weak; McLean attributes these pathologizations to a lack of attention to the socio-economic contexts that influence clients' substance use. 
Moore's (2004) study of people who inject drugs in Melbourne, Australia shows how such social and economic factors can influence harm reduction decision-making. Interviewees recounted being advised to practice various overdose prevention strategies, including using a small sample first, avoiding polysubstance use, avoiding injecting alone, calling paramedics during overdose events, and carrying naloxone. However, Moore writes "messages about overdose prevention are added to a long list of 'possible risks' encountered during the course of a typical day" (p. 1552). Although harm reduction was a priority for research participants, they explained that their ability to practice safer injecting was inhibited by the need to fulfill more immediate priorities; these included finding shelter, earning money, staying safe, avoiding withdrawal, and avoiding interactions with police (Moore, 2004). Moore's research illustrates how social inequities and interactions with the criminal justice system can limit people's options to practice harm reduction. Furthermore, Moore's study challenges the notion that unsafe using practices are the result of irresponsible decision-making, as interviewees were found to be prioritizing basic needs such as shelter, income, health, and safety.

Reclaiming personal responsibility for social justice. It is important to recognize that the concept of personal responsibility can also be utilized to further social justice for people who use drugs. According to Moore and Fraser (2006), the tenet of personal responsibility can have value within harm reduction because concepts such as "agency" and "responsibility" (p. 3038) are highly respected in Western society. The authors write that by internalizing these types of positionings, people who use substances may feel a greater sense of personal empowerment and resilience.

Faulkner-Gurstein (2017) demonstrates how this can be the case with Naloxone distribution programs. Naloxone is a medication that temporarily reverses opioid overdose 
effects. According to Faulkner-Gurstein, take home naloxone programs are a form of neoliberal governance, requiring that substance users take responsibility for attending to overdoses without concurrently requiring governments to address the root causes of the overdose crisis. However, the author points out that such programs also place a life-saving medication, and the skills to use it, in the hands of community members, therefore contributing to "collective dignity, autonomy, and mutual aid" (p. 26). Faulkner-Gurstein suggests that take home naloxone programs show the potential for neoliberal techniques of governance to be reclaimed by people who use drugs in empowering ways.

The anti-oppressive potential of harm reduction is further demonstrated by Boyd et al. (2018), who studied women's experiences accessing three overdose prevention sites (OPS) in Vancouver. Research participants, half of whom were Indigenous, described how gendered and colonial violence within Vancouver's drug scene is being amplified by the current opioid poisoning epidemic. Specifically, fentanyl-adulterated opioids quickly cause severe intoxication and loss of consciousness, and participants explained to researchers that men commonly prey on women who have experienced a fentanyl-related overdose (Boyd et al., 2018). The quick-acting, potent nature of fentanyl reduces women's ability to resist physical and sexual violence, and Boyd et al. note that Indigenous women and trans women are disproportionately targeted due to increased socio-economic marginalization. Research participants described OPS as "safe havens" (p. 2265) in which they could use drugs with a decreased risk of experiencing gendered and racialized violence. However, some participants still reported experiencing harassment from men at these sites, and Boyd et al. recommend the establishment OPS that are women-only, trans inclusive, and Indigenous-led to address this. Boyd et al.'s research demonstrates that, to a 
certain extent, the establishment of OPS can disrupt intersecting processes of gendered and colonial violence made worse by the current opioid poisoning epidemic.

Summary. Harm reduction programs focus mainly on changing individual behaviours rather than social structures, and can serve as sites of increased surveillance and social control for people who use drugs. However, people who use drugs have successfully reclaimed neoliberal harm reduction in empowering ways, and harm reduction programs focusing on behavioural change can contribute to anti-oppression. Therefore, the functioning of neoliberalism within harm reduction is nuanced, and the potential exists for neoliberalism to be resisted. Nevertheless, many scholars call for more structural approaches to harm reduction; these calls will be explored in the following section.

\section{Structural Approaches to Harm Reduction}

Many scholars critique the neoliberal harm reduction model, and advocate for an expanded conceptualization of harm reduction that addresses structural inequities (Dodds, 2002; Fraser \& Moore, 2006; Krüsi et al., 2017; Pauly, 2008; Rhodes, 2009; Souleymanov \& Allman, 2016). Pauly (2008) recommends that harm reduction workers increase our understanding of the harmful impacts of housing, social welfare, income, and policing policies on the lives of people who use drugs. Souleymanov and Allman suggest that social workers take into account how homelessness, poverty, racism, stigma, ableism, classism, heterosexism, and neoliberal restructuring generate harm for drug users. Souleymanov and Allman further call on social workers to advocate for policy changes that support anti-discrimination and increased funding for health and social programs.

Harm reduction and anti-colonialism. Historical and ongoing processes of colonialism have been implicated as a structural determinant of harm for Indigenous peoples. In a study by 
Wilson et al. (2016), Indigenous youths asserted that high rates of HIV transmission and substance use in their communities are the direct result of colonial processes that have disrupted cultures, traditions, languages, and knowledge systems. In British Columbia, the ongoing impacts of colonization are responsible for Indigenous communities experiencing higher mortality rates in the current opioid poisoning epidemic (First Nations Health Authority, n.d.); whereas Indigenous peoples account for less than 4\% of that province's population, in 2018 Indigenous peoples made up $12.8 \%$ of all overdose deaths in British Columbia (FNHA, 2019). Also in British Columbia, Indigenous people who inject drugs and live in Vancouver's DTES regularly experience anti-Indigenous racism when accessing health care and harm reduction services (Goodman et al., 2017). Many participants involved in Goodman et al.'s study revealed that they avoid the health care system in order to resist further discrimination, and explained that this often results in illnesses remaining untreated. Goodman et al.'s study demonstrates how colonization and racism within health care can increase harms for Indigenous people who inject drugs, and reinforces the need to centre anti-colonialism and anti-racism in health care and harm reduction.

The Native Youth Sexual Health Network (NYSHN) argues that current mainstream approaches to harm reduction do not fully meet the needs of Indigenous peoples (NYSHN, 2016). For this reason, NYSHN has developed a "four-fire" harm reduction model that centers anti-colonialism, and provides specific guidelines for non-Indigenous service providers working with Indigenous peoples. This model suggests that non-Indigenous service providers be aware of our roles in a legacy of trauma and violence, and demonstrate to Indigenous service users how we are actively working to disrupt that legacy. We should also be willing to support cultural activities as healing practices for Indigenous clients, while also being aware of cultural 
appropriation (NYSHN, 2016). Furthermore, we should be aware of the specific Indigenous territory we provide services within, as well as the different Indigenous communities we serve (NYSHN, 2016). Finally, NYSHN argues that honouring treaties between Indigenous Nations and settlers is as important as clinical practice (NYSHN, 2016). The four-fire model provides specific guidance for disrupting colonialism within the health care system, and serves as an example of Indigenous youth resistance against colonialism and leadership in harm reduction.

Flicker et al. (2017) provide a further example of Indigenous youth leadership within anti-colonialism and harm reduction. Flicker et al. interviewed Indigenous youth leaders about their experiences creating digital stories about HIV prevention. The authors write that, in contrast to conventional public health approaches that focus on changing individual behaviours, most of these digital stories focused instead on decolonization as an HIV prevention strategy. According to Flicker et al., these findings demonstrate the importance of expanding conceptions of HIV prevention to include support for Indigenous sovereignty movements, land preservation, cultural reclamation, and youth-elder connections.

Summary. This body of scholarship draws attention to the shortcomings of a harm reduction model that prioritizes personal responsibility above political and social change, and suggests strategies for harm reduction workers to address structural inequities through our work. This scholarship points to the ways in which ongoing processes of colonization generate harms for Indigenous peoples, and advocates for harm reduction practice that centers anti-colonialism and Indigenous political and cultural resurgence.

\section{Conclusion}

In contrast to traditional punitive and abstinence-based responses to substance use (Csiernik et al., 2017), harm reduction can be understood as an approach to working with people 
who use drugs that prioritizes public health, human rights, and social justice (HRI, 2019;

Stimson, 2007). However, some authors contend that harm reduction has become depoliticized (Roe, 2005; Smith, 2012a), and the literature demonstrates how neoliberal tenets of personal responsibility (Fraser, 2004; McLean, 2015; Moore, 2004) and surveillance (Fischer et al., 2004; Elliot, 2014) structure contemporary harm reduction service provision. In response to the neoliberal influence within harm reduction, several writers call for structural approaches to harm reduction that address underlying political, social, and economic inequities that can generate harm for people who use drugs (Dodds, 2002; Fraser \& Moore, 2006; Krüsi et al., 2017; Pauly, 2008; Rhodes, 2009; Souleymanov \& Allman, 2016). Furthermore, historical and ongoing processes of colonialism are identified within the literature as creating harm for Indigenous peoples (FNHA, n.d.; Wilson et al., 2016), and therefore some authors advocate for harm reduction initiatives that support Indigenous political and cultural reclamation (Flicker et al., 2017; NYSHN, 2016).

Based on this analysis of harm reduction scholarship, I have identified the following gaps in the existing literature: Firstly, although several writers advocate for structural approaches to harm reduction, there is a lack of scholarship examining the actual practices that harm reduction workers engage in to pursue this goal. Secondly, there appears to be a limited amount of scholarship written by social workers on the subject of harm reduction; of the literature surveyed in this chapter, only Csiernik et al. (2017) and Souleymanov and Allman (2016) write from a social work perspective. Thirdly, the existing Canadian harm reduction scholarship focuses disproportionately on Vancouver; of the literature examined in this chapter, only Bardwell et al.'s (2019) study was conducted in Toronto. By utilizing a social work perspective to investigate 
anti-oppressive harm reduction practices in Canada's largest city, this research project attempts to address these gaps in harm reduction and social work scholarship. 


\section{CHAPTER 4. METHODOLOGY}

This research utilizes a qualitative, interpretive phenomenological methodology to investigate how harm reduction workers address structural processes of oppression through their work. I selected a qualitative methodology as the purpose of this study is not to generate facts, but to develop understandings (Strega, 2015). Qualitative research may also align better with the epistemological and ontological assumptions of anti-oppressive theories, which understand knowledge to be subjective and rooted in lived experience (Moosa-Mitha, 2015).

I have chosen to use a phenomenological methodology as my research attempts to make meaning from the common, lived experiences of a group of people (Creswell \& Poth, 2018; Flood, 2010; Hopkins, Regehr, \& Pratt, 2017). In order to accomplish this, phenomenological researchers try to move beyond our familiar, taken-for-granted perspective on the world known as "natural attitude" (Hopkins et al., 2017). Instead, researchers adopt a "phenomenological attitude", through which we critically reflect on our assumptions, restrain our preunderstandings, and attempt to be open to different ways of understanding (Hopkins et al., 2017; Finlay, 2008). Phenomenologists accomplish this through a process known as "bracketing" (Flood, 2010).

There are two main schools of thought within phenomenological research: descriptive and interpretive. The goal of descriptive phenomenological research is to describe the essence of a phenomenon; that is, to describe a phenomenon in the purest form in which it is experienced by individuals, without interference from preconceived understandings (Tuohy, Cooney, Dowling, Murphy, \& Sixsmith, 2013). This approach contains the following ontological assumptions: that there can exist a single correct interpretation of reality which can be universally experienced, and that reality is uninfluenced by social context (Flood, 2010; Preston \& Redgrift, 2017). 
Epistemologically, the descriptive approach assumes that the researcher's prior knowledge and experience can and must be set aside in order to describe the essence of the phenomenon under investigation (Wojnar \& Swanson, 2007). For descriptive phenomenologists, the process of bracketing is used to set aside all preconceived ideas, in order to approach the phenomenon from a perspective of objectivity (Tuohy et al., 2013).

Rather than focusing on description, interpretive phenomenologists seek to interpret people's experiences of a phenomenon, in order to elucidate meaning (Tuohy et al., 2013). Ontologically, this approach assumes that reality is contextual and co-constructed by the individual and the social world in which we inhabit (Hopkins et al., 2017). From this ontological position a single universal essence cannot exist. Instead, interpretive phenomenologists search for patterns and themes, while recognizing the subjective experiences of individuals (Langdridge, 2008; Preston \& Redgrift, 2017). As reality is understood to be co-constituted, the knowledge and experience of the researcher is not held in abeyance, but is instead utilized to coconstruct meaning in conjunction with research participants (Preston \& Redgrift, 2017). However, it is crucial that researchers reflect critically on our own power and positioning throughout this process. Interpretive phenomenologists therefore use bracketing as a critically reflexive process (Tuohy et al., 2013), in order to understand how our knowledge and experiences shape our interpretations of the research (Preston \& Redgrift, 2017), and to better ensure that our perspective does not dominate or marginalize the knowledge and experiences of research participants (Finlay, 2009). I have selected interpretive over descriptive phenomenology for this study as I believe the epistemological and ontological assumptions of interpretive phenomenology better align with AOP's understanding of knowledge and reality as subjective and co-constructed (Moosa-Mitha, 2015; Preston \& Redgrift, 2017). 


\section{Recruitment}

Research participants were selected through a purposeful sample, based on their understanding and relationship to the phenomenon being studied (Creswell \& Poth, 2018). I conducted the purposeful sample by emailing recruitment posters (see Appendix A for recruitment poster) to social service agencies in Toronto that provide services from a harm reduction perspective. I also sent emails (see Appendix B for email script) to harm reduction workers in my professional network, who then passed on recruitment handbills (see Appendix C for recruitment handbill) within their networks. Individuals had to meet the following criteria in order to participate in this research project: they must have been working in the field of harm reduction, or must have worked in the field within the last three years; they must have worked in the City of Toronto; and they must have been at least 18 years old. Five people contacted me to participate in this study; however, two of these individuals ceased contact before scheduling interviews. These individuals did not inform me of their reasoning for this, as was their prerogative. The remaining three people consented to be interviewed for this study.

\section{Data Collection}

I utilized in-depth, semi-structured interviews to collect data, as this method allows participants to describe their lived experiences with a phenomenon as freely as possible (Brinkmann \& Kvale, 2015), and allowed me the flexibility to follow up on interesting experiences as they came up in interviews (Smith, 2004). I developed an interview guide to facilitate data collection (see Appendix D for interview guide), and followed Preston and Redgrift's (2017) recommendation to include a mix of broad questions and probing questions. The interview guide covered topics such as the meaning of harm reduction, the role of antioppression in harm reduction work, and harm reduction practice in the current opioid poisoning 
epidemic. Two interviews took place in May 2018, and one in June 2018. I conducted two interviews at Ryerson University's Student Learning Centre, and a third interview took place at a participant's place of work. Interviews lasted 1-1.5 hours in length, and were audio-recorded. I transcribed each audio recording verbatim within one week of interviews taking place, and then permanently deleted the recordings. Research participants were given the option to receive a copy of their transcripts; one participant asked for this.

\section{Data Analysis}

I analyzed data following Smith, Flowers, and Larkin's (2009) procedure for interpretative phenomenological analysis (IPA). Using this approach, data is analyzed on a caseby-case basis, after which the researcher searches for patterns across cases in order to develop themes (Smith et al., 2009). According to Smith (2017), a benefit of this approach is that it allows for an idiographic interpretation of research data; that is to say, focus is maintained on the unique experiences of individual research participants, and commonalities and differences of experience are explored within themes.

Bracketing. I first engaged in a process of phenomenological bracketing, in order to critically reflect and make more apparent how my professional and personal experiences with harm reduction could impact my interpretation of the data. I took a large sheet of poster paper, and using a black marker wrote "my relationships to harm reduction" in the center. Then, using coloured markers, I wrote different words and phrases, and drew symbols and pictures. I posted the sheet on the wall above my workspace, and some of the results of this activity are described in the introductory chapter of this MRP.

Developing codes. I began by re-reading transcripts, in order to gain a better sense of participants' experiences (Smith et al., 2009). I then printed out the transcripts and manually 
coded with a pencil. During this process I followed Saldaña's (2009) suggestion to draw line breaks separating long passages of text into smaller units for coding. I used my research question and theoretical framework as guides to develop codes, and coded units of text based on their relationship to harm reduction practice, as well as theories of neoliberalism and anti-oppressive practice. I applied both In Vivo and descriptive codes to these smaller units of text; the former are exact words taken from the transcript and placed in quotes, whereas the latter summarize the meaning of a particular excerpt of data (Saldaña, 2009). I manually wrote codes in the right margin of transcripts, and initially generated 78 codes from all three transcripts. I then engaged in a round of consolidation (Saldaña, 2009), combining similar codes together, after which I was left with 39 codes. I recorded codes with accompanying textual examples and memos (Creswell \& Poth, 2018) in an electronic codebook (Creswell \& Poth, 2018).

Developing themes. Thematic development was both visual and tactile. I printed out the codebook and, using scissors, cut out each example of code and accompanying text. I then glued these to pieces of coloured poster paper; a different colour was used for each research participant. Proceeding on a case-by-case basis, I manually grouped the coded texts into emergent themes, following Smith et al.'s (2009) recommendation to search for interrelationships, connections, and patterns between coded data. After this step, I again manually moved around participants' data, this time looking for patterns and similarities across the three cases (Giwa \& Greensmith, 2012). As with coding, I utilized my theoretical framework as a lens during thematic development. From this process I developed three superordinate themes comprised of data from all participants: conceptualizing harm reduction beyond personal substance use; peer engagement and mobilization; and challenging incarceration, policing, and surveillance. 


\section{Critically Reflecting on the Absence of Anti-Colonialism in the Findings of this MRP}

Only one participant discussed the topic of anti-colonialism within harm reduction.

During data analysis I developed an emergent theme for these data, which I labelled "addressing colonialism”. However, as the other two participants did not address anti-colonialism, I was unable to combine this emergent theme with similar data from the other participants to create a superordinate theme. I attempted to re-organize themes, and also searched for interrelationships, connections, and patterns (Smith et al., 2009) between the emergent theme of "addressing colonialism" and the three superordinate themes; however, I did not perceive a way to include these data within the superordinate themes. Therefore, although one participant touched on the topic of anti-colonialism within harm reduction, these data are not included in the findings of this MRP.

I must implicate my own recruitment and data collection methods in producing these results. I did not send recruitment material to Indigenous agencies, and it is possible that Indigenous harm reduction workers would address anti-colonialism differently than the white settler harm reduction workers I interviewed. Furthermore, I did not include a question in my interview guide that specifically asked participants to discuss anti-colonialism. I made this decision because I believed it would be in keeping with a "phenomenological attitude" to allow participants to discuss whichever anti-oppressive practices came to mind. Instead, during interviews I read out a list of oppressions that included "colonialism", and asked participants to comment on issues of oppression in harm reduction (see Appendix D for interview guide). As discussed in the theoretical framework of this MRP, a major critique of anti-oppressive practice is that it can de-center anti-colonialism (Baskin \& Davey, 2017; Yee \& Wagner, 2013). I am 
complicit in de-centering anti-colonialism within AOP research, by not explicitly asking participants in this study to discuss anti-colonialism.

\section{Ethical Considerations}

The Ryerson University Research Ethics Board approved this study (see Appendix E for ethics approval). Written consent was obtained from all research participants prior to the commencement of interviews (see Appendix F for consent form). Participants were informed both in writing and verbally of their right to withdraw consent; had anyone exercised this right, I would have immediately destroyed their data. All data and consent forms will be destroyed one year after submission of this MRP.

Participants were informed that this research project carried a minimal level of psychological risk, such as negative emotional responses that could result from recounting work experiences in the harm reduction field. To reduce this risk, participants were informed both in writing and verbally that involvement in this study was voluntary, and that they could skip questions, pause, or end the interview at any point. No participant chose to exercise this right. Furthermore, all participants were provided with a list of free support services prior to the commencement of interviews. Participants were also informed that this research project carried a minimal level of social risk. Participants were asked to speak frankly about positive and negative work experiences. If their identities become known to colleagues who read this MRP, they could potentially experience loss of privacy, embarrassment, or damage to reputation. In order to reduce this risk participant names have been replaced with pseudonyms, and worksites are unnamed in this MRP.

\section{Participants}


I interviewed three harm reduction workers for this study. Riley is in his early thirties, identifies as a cisgender, queer, white settler, and comes from a middle class background. $\mathrm{He}$ holds a master of social work degree, and works at an overdose prevention site. James is in his mid-forties, and identifies as a gay, white, male. He studied social service work at a local community college, has worked and volunteered in the harm reduction field for over a decade, and holds a peer outreach position with an HIV/AIDS service organization. Catherine is a white queer in her early twenties, holds a bachelor of social work, and intends to pursue a master's degree in the field. Catherine works at a community health centre (CHC). All participants reported learning about anti-oppressive practice in their social work and social service education. 


\section{Chapter 5. Findings}

Based on an interpretative phenomenological analysis of interview data, three themes emerged detailing how research participants understand and address structural processes of oppression through their harm reduction work. The first theme, conceptualizing harm reduction beyond personal substance use, describes how participants understand and practice harm reduction in ways that go beyond the dominant model's singular focus on health behaviours. The second theme, peer engagement and mobilization, explores the ways in which research participants center the perspectives of people who use drugs. The third theme, challenging incarceration, policing, and surveillance, highlights the strategies undertaken by participants to challenge the role of the criminal justice system in the lives of people who use drugs.

\section{Theme One: Conceptualizing Harm Reduction Beyond Personal Substance Use}

This theme examines how participants apply the concept of harm reduction to a broad range of activities extending beyond personal substance use. I began each interview by inviting research participants to articulate their understanding of harm reduction; notably, none of the participants responded with the common definition that harm reduction applies only to reducing the harms of individual substance use. While all participants spoke at various points of the importance of addressing specific harms related to using substances, they also spoke of the need to change discourse and address structural inequities in order to mitigate harms for people who use drugs.

When asked to describe the meaning of harm reduction, James firmly rejected the assumption that only people who use drugs engage in harm reduction, and instead normalized harm as a phenomenon experienced by everyone in society: "Basically what it says. Reducing 
any harms or potential for harms. An example would be sunscreen, which would protect you from harmful UV rays. Or a bike helmet. Or a seatbelt."

Only after making certain that I understood that harm and harm reduction are universal phenomena did James move the discussion to the harms specifically experienced by people who use drugs. However, instead of talking about the harms associated with substance use, he pointed to the oppressive language that is often used to describe substance users, identifying language as a source of harm and a site of harm reduction practice:

James: We all have to be very careful with language that we use- crackhead, things like that. Junkie. Clean.

Travis: Why do we have to be careful about that?

James: Because that perpetuates the stigma and the judgements associated with substances and people who access harm reduction. Language is so key when trying to break down barriers and open up doors and services and people's access to services. If you start saying "are you a meth head?" -come on! People who practice harm reduction actually sometimes say "okay, look, there is a better way to say this". And we're learning all the time, language is changing all the time. And language can be completely harmful. I can think of so many harmful ways to say something that I can think of saying in a nicer, more inclusive way. I do it all the time. All the time we should be conscious of the language we use, a lot of it's older language that's more oppressive.

Like James, Catherine described harm reduction practice as applicable beyond substance

use. While noting the importance of reducing health risks associated with individual behaviours,

Catherine understands such risks to be generated largely by an oppressive socio-political and economic system, rather than the result of individual pathology:

Harm reduction practices I think can apply to a lot of different things in everyday life, whether it's using drugs, whether it's using other coping mechanisms like self harm or sex, or whether you're in your job and you want to reduce the harm of your job. Like, I think harm reduction frameworks can be applied to a lot of things. I think of it, you know, the practicalities of keeping yourself safe and healthy as an individual but also protecting yourself from the system that might criminalize you or oppress you.

Catherine has observed that many service users understand their substance use as a personal failure. As part of her professional harm reduction practice, she sometimes works on a 
discursive level with service users to develop alternative narratives to reframe substance use as a response to processes of trauma and oppression:

I see a lot of self blame or helplessness. Like, "my doctor says I have an addictive personality blah blah blah". And I try to reframe it as maybe you are coping right now, because bad things have happened to you, and that could be addressing sexual abuse and misogyny, it could be coping with racist violence. And just saying, you know, you have support here and we want you to help keep your body as healthy as you can by, like, using sterile supplies, but you know, if this is what you're doing right now to cope, instead of framing it as a fault in the person, reframing it as circumstantial. Realizing that people can only deal with so much bullshit before they need something to cope and for some people that's drugs.

Similar to the other participants, Riley also defined harm reduction philosophy as

applicable beyond substance use. Riley described harm reduction as a recognition of the personal agency of people who use substances. For him, harm reduction practice involves respecting the knowledge and decision-making capacities of substance users, while at the same time working to structure society in ways that ensure the social inclusion of people who use drugs:

$[\mathrm{H}]$ arm reduction is a way of centering people's autonomy and choice in how they want to navigate the world, but it's also got to be a way of structuring an environment or society to accommodate, or not accommodate, because accommodate suggests that somehow there's something, like, natural about most people and that people who use substances fall out of that. But maybe just to build a just society that doesn't neglect this group of people.

The responses within this theme demonstrate how participants conceptualize harm reduction practice as extending beyond personal substance use. James pointed out that harm reduction is a universally experienced phenomenon, and both he and Catherine discussed discursive practices as harm reduction. For Riley, harm reduction means respecting the autonomy of people who use drugs, as well as actively working to create a more inclusive society. Together, these participants challenge the dominant understanding of harm reduction as applicable only to personal substance-using behaviours.

\section{Theme Two: Peer Engagement and Mobilization}


This theme explores the ways in which participants center the involvement of people who use drugs within harm reduction. Participants provided examples of engaging and mobilizing people who use drugs in the areas of direct practice, organizational policy development, and political action.

For James, the involvement of people who use drugs within service delivery is a key harm reduction principle. As a peer worker who provides services within his own community, he spoke from a position of epistemic privilege on this topic, meaning that he may have more immediate, insider knowledge (Narayan, 1988) about substance use and harm reduction than workers without lived experience. James feels that he can more meaningfully engage with other community members in ways that go beyond simply distributing harm reduction supplies:

I work with people I know, and that I support in other ways, also. It's not just- "here's a supply, tick off my outreach box, done." I know a lot more about the people I engage with. A lot more. I'll know where they're sleeping, I'll know what they do, I'll know what they want.

James provided an example of peer support from his outreach work, when he traded shoes with an individual as a crisis de-escalation strategy. This example illustrates how peer workers can respond in creative ways that may not be possible for other harm reduction workers:

I traded a guy his shoes, he was so paranoid that the police were coming to the parks and stuff, and that's where I was hanging out. And he was so afraid of the police that he was like walking around in his socks because he took off his jail shoes, right? They're jail shoes, that's what they are. Blue and white. Anyway, I'm like where are your shoes? This is what an outreach worker does. Where are your shoes? Oh I left them in the bathroom because the fucking cops, they're staring at me and they're going to arrest me again. So I went into the washroom, I grabbed his shoes, they were just on the floor, I put them on right away and went back outside and I was like here man, here put these on. Who cares. Maybe not the best idea to share shoes, but at the time this guy was having a crisis and seemed distraught so I traded my shoes.

James went on to state his belief that community members need to occupy more leadership positions within harm reduction programs, as peers are best able to identify and meet 
the needs of their own communities. He is critical of organizations that do not reflect the diversity of the communities they serve:

$[\mathrm{H}]$ opefully programs can be peer lead whenever possible. And I think there's enough substance users, there's enough people who have experienced poverty or homelessness that can speak to the issues at hand, from a lived experience point of view. As opposed to going to a program that deals with homelessness, poverty, and stigma and not one of those motherfuckers have ever, ever. And they also work with Indigenous communities and don't even have an Indigenous person on their staff. What? I'm like, what? What are you? Who are you? Who do you think you are? Coming in and representing a community that you're not even from.

Riley also articulated the importance of centering people who use drugs within harm reduction. For him, it is important that harm reduction organizations take the time to build relationships with the communities they serve. Furthermore, Riley expressed the need for community members themselves to provide services within these programs: "harm reduction needs to look at building relationships with people, like being part of the community and, like, having community members be comprising the group of people who are providing harm reduction services.

Riley is mindful that he and other workers at his organization are guests within the community. Keeping this positioning in mind, he and other harm reduction workers intentionally step back to allow community members to make decisions on how the space operates:

I think literally being on Indigenous land, being in [...] this neighbourhood that's had a long history of being criminalized for drug use, and poverty is sort of synonymous with that area. Yeah, it's like reminders that the space wasn't ours, or we're a guest in this house. Just, like, trying to keep that in mind as we structure things going forward. And I think that having a group of people who are community members, who are making community agreements for the space, tried to account for those things.

For Catherine, peer engagement took the form of political mobilization. Our interview took place during the 2018 Ontario provincial election, and Catherine spoke of plans to use artmaking as a means to engage community members in the electoral process: 
I might work to start an art group here. Specifically I'm mobilizing to get people out to vote right now. And I was like maybe we can do some art around that, maybe we can do some posters around that.

She spoke further about her work to mobilize community members to vote in the election. She voted early, in order to better understand and explain the process to clients:

I like to go and do things practically. Like, I went to vote yesterday, so that I could know the process. And, like, I went with someone and there were barriers there, and just, like, being able to have that experience, so you know a bit more about what to expect. So that's part of my work, too.

Catherine articulated a connection between voting and harm reduction. She noted that Progressive Conservative leader Doug Ford made comments during the election campaign opposing harm reduction approaches to substance use, and speculated that his electoral victory could result in increased opioid overdose deaths:

[T]he election is very relevant. Doug Ford has said he doesn't believe in safer injection sites, so if he chooses to act on that, that means people lose jobs and overdoses will increase. The number of recorded overdose deaths in 2017 is in the thousands.

The responses contained within this theme illustrate how participants engage people who use drugs as part of their harm reduction work. For James, this is demonstrated by his lived experience providing peer outreach services. As a social worker, Riley keeps a mindful positioning that he is a guest in the community he works within, and supports the involvement of service users in creating policy for his organization. For Catherine, peer engagement took the form of political mobilization during the 2018 Ontario election. These findings demonstrate that centering the voices and perspectives of people who use drugs is a key harm reduction principle for participants of this study.

\section{Theme Three: Challenging Incarceration, Policing, and Surveillance.}

The final theme of this study highlights how research participants take a critical stance against the criminal justice system and the role of harm reduction in policing the behaviours of 
service users. This theme examines the tactics participants use to challenge the power of the criminal justice system, as well as practices they have developed as alternatives to policing the lives of people who use drugs.

Some of the participants of this study expressed how, for them, opposing the criminal justice system is an important aspect of harm reduction. This is demonstrated by a quote from Riley, who spoke of the need for harm reduction to support the prison abolition movement, and to support efforts to reduce police power:

I think that harm reduction has to be paired with a prison abolitionist stance, a stance that looks to disarm and take power away from police, and through that trying to stop the disproportionate criminalization of people of colour, trans people, sex workers, people who are currently facing stuff from the system.

Catherine also made a connection between harm reduction and the prison abolition movement. She opined that criminalization can increase harms and risk-taking for people who use drugs:

If people are criminalized because they're using drugs they might be more likely to hide, get hurt, there might be more of an attitude of "well, fuck it. People are going to treat me like a criminal." So yeah, I definitely think that prison abolition aligns with harm reduction.

Expanding on her critique of the carceral system, Catherine expressed her opinion that prisons do not perform a rehabilitative purpose, but rather function to disappear and contain specific marginalized groups within society:

And again, if you look at prisons, it's where you put people that no one really wants to deal with. And when you look at the population inside prisons, it's a lot of Indigenous folks, a lot of Black folks, a lot of people with mental illnesses and brain injuries. And a lot of women in prison are there for petty crimes, or responding to violence.

Catherine signals her support for prison abolition to clients and co-workers by displaying a poster in her office with the words "Queers Demand a World Without Prisons", which 
surround an image of birds flying over a barbed wire fence. When asked about the significance of the poster, she spoke of the need to dream of a better world, as a necessary component of harm reduction:

I try to put some dreamy shit around my office. Like, dreaming is a part of survival, I think. It is important for people to realize, because if we're just going through the checklist of, like, food, housing, clean needles or whatever, that's not, that's not much of a life.

Participants were also critical of the role of policing in the lives of service users.

According to Riley, "There's no situation in which policing is going to result in a positive health outcome for the people involved- their job is to surveil and persecute people who use substances." For this reason, it is important for Riley and his colleagues to avoid police involvement at the OPS:

In structuring the space we came across issues of racism, sexism, and violence would happen, and I think it was important for us to have, like, principles like- don't call the cops, ever. We don't call the cops, we call ambulances sometimes if after a few shots [of naloxone] someone is still in rough shape, but yeah, that's a conscious decision- we need to try to create things that are not, like, just falling back on the shitty things about the criminal justice system.

Rather than relying on Toronto police to de-escalate conflicts that periodically occur between service users at the OPS, Riley expressed confidence in service users' own conflict resolution skills: "So you would see people in the community de-escalating other people constantly. Just breaking things up. And that was I think to me a reason for noninterventionism."

However, Riley also pointed out that, in keeping with client-centered practice, he will respect the wishes of service users when deciding whether to involve the police in conflict resolution. He noted though that service users themselves often do not desire police involvement at the OPS: 
[T]here have been times where after breaking up a fight or something we will talk to a person and say what do you need and they say I need to go to the hospital or I want to file a police report then I guess we would call the cops, but I think that's different than looking at the state as a go-to response that will solve things. And again, from what our experience has shown, people don't want those responses because they feel that they are dealt with inadequately.

Whereas Riley looks for alternatives to utilizing the police in his work, Catherine has made attempts to educate co-workers at the community health centre about police brutality. She recounted one such conversation with a co-worker who was critical of Toronto Pride's decision to bar uniformed police officers from participating in the city’s 2017 and 2018 Pride parades. Catherine used this as an opportunity to highlight the role of police violence in the lives of many people of colour, queer people, and trans people. She did this by bringing up the historical example of the 1969 Stonewall riots:

Like, the other day I had a discussion with someone I'm working with and he was talking about, like, "the gays" having made a bad decision about asking the cops not to march in the parade. And then I talked to him about Stonewall, and the context of Pride as originally a struggle by the most marginalized people, trans folks, sex workers, folks of colour, against police brutality. So that kind of shifted things for him. He was receptive because we have a good relationship.

James' critique of policing focused on the ways in which harm reduction workers are sometimes expected to police and surveil the behaviours of people who use drugs. James specifically discussed the power of uniforms and other identifying apparel some agencies require harm reduction workers to wear. He resists wearing such clothing when engaging in outreach work, as he does not want to perpetuate hierarchical power dynamics:

James: I refuse to wear those outreach uniforms. I refuse, I refuse.

Travis: Why do you refuse?

James: Because I don't come in and ride my bike as if I'm a wannabe police officer. 
When asked to explain this reasoning, James explained that many people within his community have had negative experiences with police officers and other officials in positions of authority. Consequently, it may be unnerving for community members when harm reduction workers wear clothing that conveys authority:

Well, some people have a problem with authority. I've seen people who are drunk get very pissed off, for whatever reason, maybe history, with the cops. And these uniforms, I've seen people want to fight people just because they have the word security written on their backs- "oh, you're security? You think you're so tough?" Stuff like that. And especially people who I'm guessing who have been incarcerated before.

James noted that unhelpful hierarchies often exist between workers and community members, and pointed out that outreach workers will sometimes take on the work of police officers in regulating community members' substance use in public spaces:

You're separating yourself from the community. In fact, people who see other people in uniform? Not helpful. And people who perceive someone else in a position of authority? Not helpful. And when you think you're in a position of authority and you're telling someone to dump out their beer because you're a harm reduction worker, or telling them they have to leave the park? That's not your job.

James further pointed to the discursive power of uniforms, and argued that such markers

of authority may serve the personal interests of social service workers at the expense of community members:

As empowering as wearing the outfit might feel to people, that's a selfish reason. Outreach is when you're reaching out to other people, it has nothing to do with you. It has something to do with you because it might make you feel better, but if it's counterproductive, then you need to recognize that. And people and policies need to know that. Is it necessary, what is the reason behind it? And what are the ramifications for people who see you wearing that? It's again, it's close to language, it's a type of language maybe, which could be a barrier to people.

The responses within this theme demonstrate how participants take a critical stance against the social control of people who use drugs. Catherine accomplishes this by visibly signaling her support for prison abolition, and also engaging a co-worker on the topic of police brutality. Rather than relying on the police to manage conflicts, Riley supports service users to 
engage in conflict resolution. James resists policing the behaviours of his community members, and refuses to wear clothing that conveys authority. These responses suggest that participants resist the criminalization and surveillance of people who use drugs.

\section{Conclusion}

The findings of this study indicate that research participants understand and address structural oppressions through harm reduction in the following ways: by conceptualizing harm reduction beyond personal substance use, by supporting peer engagement and mobilization efforts, and by challenging the incarceration, policing, and surveillance of people who use drugs. In the following chapter I will examine these findings in relation to the scholarship analyzed in the literature review of this MRP, as well as to theories of neoliberalism and anti-oppressive social work practice. 


\section{CHAPTER 6. DISCUSSION}

This study has investigated how harm reduction workers in Toronto address structural processes of oppression through their work. Through a phenomenological analysis of participant responses, three themes were developed from the interview data: conceptualizing harm reduction beyond personal substance use; peer engagement and mobilization; and challenging incarceration, policing, and surveillance. In this chapter I will explore the results contained within these themes as they relate to the literature on the meaning of harm reduction, and then I will analyze the findings in relation to the scholarship on neoliberalism and anti-oppressive social work practice. I will conclude this chapter by detailing the limitations of this study.

\section{The Meaning of Harm Reduction}

Jiao's (2019) analysis of the philosophical underpinnings of harm reduction can be utilized to interpret the findings of this research. Jiao divides harm reduction practice into two approaches: technical and social. According to Jiao, the technical approach privileges biomedical knowledge as a singular truth, understands risk and harm as originating within the epidemiology of substance use, and reflects a post-positivist knowledge paradigm. In contrast, the social approach privileges the experiential and contextual knowledge of people who use drugs, understands risk and harm to originate within the social and political environment, and reflects constructivist and critical knowledge paradigms (Jiao, 2019).

The findings of this study show that participants understand risk and harm to be amplified by social processes that contribute to oppression. For example, James identified stigmatizing language as causing harm, both Riley and Catherine discussed the harm created by prisons and policing, and Catherine speculated that a Progressive Conservative election win would increase harm for people who use drugs. These responses demonstrate that participants in this study 
ontologically locate risk and harm within the social and political environment, rather than solely within the epidemiology of substance use. It is unclear though if all participants base their epistemological understandings of risk and harm on the experiential and contextual knowledge of people who use drugs. Certainly, James was speaking as someone with lived experience, and Riley indicated that his critique of policing was informed in part by service users' desire to limit police presence at the OPS. In contrast, Catherine attributed harm to policing, incarceration, and criminalization, yet did not say whether this was based on service users' knowledge or her own perceptions. Nonetheless, based on participants' articulations of the social and political contexts that generate harm for people who use drugs, it appears that participants in this study practice harm reduction more in accordance with Jiao's (2019) social approach than the technical approach.

The findings of this study challenge the argument put forth by Roe (2005) and Smith (2012a) that harm reduction has become depoliticized through its incorporation into mainstream public health. Smith contends that the depoliticization of harm reduction is demonstrated by the absence of a structural analysis within the field, yet participants articulated clear connections between substance use, harm, and broader historical, political, and social forces. This is demonstrated by participants' understandings of harm reduction described within theme one: conceptualizing harm reduction beyond personal substance use, as well as their critiques of policing and imprisonment within theme three: challenging incarceration, policing, and surveillance. According to Roe, the depoliticization of harm reduction is also marked by the privileging of biomedical knowledge over the experiential knowledge of people who use drugs. Although I have suggested above that the degree to which participants privilege experiential knowledge may be limited, the findings within theme two: peer engagement and mobilization 
show that participants nonetheless make attempts to take experiential knowledge into account. Specifically, James is a peer outreach worker who utilizes his experiential knowledge to support his community, and Riley discussed how service users have created guidelines for his organization. Furthermore, Catherine's voter mobilization work can be understood as an effort to amplify the voices of people who use drugs during the 2018 provincial election, and serves as an example of politicized practice in its most literal sense. While the depoliticization of harm reduction may be more evident at the policy level, as demonstrated by policy documents lacking politicized content (Government of Canada, 2018; Hyshka et al., 2017; Ministry of Health and Long-Term Care, 2018), the findings of this study suggest that harm reduction practice itself can be political, even within a conservative policy environment.

\section{Neoliberalism}

Harm reduction and social control. Within neoliberalism, the retrenchment of the welfare state is accompanied by the expansion of the criminal justice system, which is utilized to manage and contain the social and economic inequities generated through neoliberal restructuring (Wacquant, 2009). In accordance with neoliberal logic, both social work and harm reduction can function to surveil and regulate marginalized groups (Elliot, 2014; Fischer et al., 2004; Pollack \& Rossiter, 2010; Pon et al., 2011; Souleymanov \& Allman, 2016; Wacquant, 2001), therefore extending the reach of the criminal justice system into social service provision. Furthermore, the criminalization of people who use drugs can be understood as a neoliberal response to substance use (Dollar, 2018; Gordon, 2006).

However, as demonstrated within theme three, participants in this study were critical of the criminal justice system, and found ways to challenge its role in the lives of people who use drugs. Each participant described different tactics to accomplish this. For Catherine, this 
involved prison abolition advocacy and educating a co-worker about police violence. Riley supported alternatives to relying on police for conflict de-escalation, in particular by recognizing and supporting service users' own conflict resolution skills. James expressed his refusal to participate in the surveilling of his community. These practices suggest that research participants resist the role of social work and harm reduction in augmenting the work of the criminal justice system to surveil and control people who use drugs, thereby challenging the neoliberal principle of social control. These practices can also be understood as opposition to the criminalization of people who use drugs, and thereby challenge neoliberalism as it operates through the war on drugs users.

The literature suggests that surveillance and policing practices can negatively impact the well-being of people who use drugs. For example, one of the findings in Moore's (2004) study was that unsafe injecting practices were associated with a need to avoid police contact. As well, Bardwell et al. (2019) found that a heavy police presence in the vicinity of a Toronto SIS discouraged people from accessing the site. Given that SIS are saving lives during the current opioid poisoning epidemic (Irvine et al., 2019), policing practices that inhibit access to SIS may be detrimental to the health of people who use drugs. Taking a critical stance towards the criminal justice system, as participants in this study do, may therefore be one useful strategy to support the health and safety of drug users, and is in line with Pauly's (2008) recommendations for harm reduction workers to educate ourselves on the harmful impacts of policing policies.

Harm Reduction and personal responsibility. The neoliberal tenet of personal responsibility is evident within the dominant harm reduction model, which understands risk and harm to result mainly from personal substance-using behaviours, while largely ignoring structural determinants of harm (Fraser, 2004; Miller, 2001; Moore \& Fraser, 2006; Rhodes, 
2009; Souleymanov \& Allman, 2016). The dominant harm reduction model therefore prioritizes substance users' responsibility to change their behaviours (Krüsi et al., 2017), and this perspective can obscure historical, political, and socio-economic factors that contribute to health inequities (Ayo, 2012; Duggan, 2003).

Participants in this study appear to challenge the neoliberal tenet of personal responsibility in several ways. The findings of theme one show that none of the research participants understand harm reduction as solely a matter of altering personal behaviours. Within this theme, Riley spoke of a societal responsibility to both respect the autonomy of people who use drugs, as well as to work towards social change. James and Catherine located harm within oppressive language and discourse rather than individual substance use. Within theme two, Riley and James both discussed the need to incorporate peer knowledge, highlighting the organizational-level responsibility of harm reduction agencies to privilege the experiential knowledge of people who use drugs. Additionally, Catherine's voter mobilization efforts within this theme point to the need to effect change at the macro/political level, not just the micro/individual. Finally, the findings of theme three suggest that research participants identify the criminal justice system as a structural determinant of harm for people who use drugs. The practices described within all three themes challenge the neoliberal tenet of personal responsibility by focusing attention on the social and political dimensions of substance use. Furthermore, many scholars argue that people who use drugs can become pathologized when the structural contexts that influence substance use are ignored (Foth et al., 2015; Krüsi et al., 2017; McLean, 2015; Moore \& Fraser, 2006; Pauly et al., 2015; Rhodes, 2009; Souleymanov \& Allman, 2016). By considering the social and political contexts of service users' lives, participants in this study may be challenging the pathologization of people who use drugs. 
Peer outreach and personal responsibility. Faulkner-Gurstein (2017) points out that peer-based initiatives embody neoliberalism by assigning responsibility to people who use drugs for the health and safety of their communities, while absolving governments of the responsibility to develop structural responses to inequity. According to this analysis, James' peer outreach work can be interpreted as a neoliberal response to substance use, as he and other peers are tasked with the responsibility to look after the health of their community. However, FaulknerGurstein argues that peer-based initiatives can contribute to community capacity-building and mutual aid, and therefore represent a reclaiming of neoliberal tactics in support of social justice. James' peer outreach work should be understood with this in mind, as a reclamation of personal responsibility that centers experiential knowledge and community capacity-building.

\section{Anti-Oppressive Practice}

Politicized Practice. Participants in this study engage in politicized harm reduction practice, which I have discussed above in relationship to scholarship by Roe (2005) and Smith (2012a). AOP theorists call for political practice at both the micro and macro levels (Baines, 2017a; Barnoff, Abdillahi, \& Jordan, 2017; Karabanow, 2004; Ross, 2017; Strier \& Binyamin, 2010); however, based on the findings of this study, most of the practices described by research participants appear to be at the micro (individual) and mezzo (organizational) levels. Only Catherine's voter mobilization efforts can be understood as clearly macro-level, and this may support Ross' (2017) claim that structural-level actions have become more challenging within the current neoliberal environment. However, by engaging in a variety of forms of politicized practice, research participants appear to value the political potential of micro and mezzo-level initiatives, and therefore take a "big tent approach" (Ross, 2017, p. 314) to harm reduction practice. 
Peer involvement. AOP scholars advocate for the meaningful involvement of people with lived experience within social service provision (Barnoff, Abdillahi, \& Jordan, 2017; Dumbrill \& Yee, 2019; Karabanow, 2004; Larson, 2008; Pollack, 2004; Strier \& Binyamin, 2010), and further call for social service agencies to be directly accountable to the communities they serve (Barnoff, Abdillahi, \& Jordan, 2017; Strier \& Binyamin, 2010). To a certain extent, some of the participants in this study described practices that reflect this AOP principle. James' peer outreach work with the HIV/AIDS service organization is an example of the privileging of experiential knowledge within frontline service delivery; however, James did not indicate that his or other peers' knowledge is incorporated into leadership or decision-making within his organization. Riley described how service users created a set of guidelines at the OPS, but did not provide further examples of peer decision-making. Catherine did not discuss peer involvement at the $\mathrm{CHC}$.

However, I am familiar with these three harm reduction organizations, and am aware that they all operationalize peer knowledge to a greater degree than what was discussed by interviewees. I find it puzzling that participants did not discuss further ways in which peers are involved in these organizations. By limiting their discussions regarding peer involvement, it is possible that some research participants do not personally conceptualize peer knowledge as a central tenet of anti-oppressive practice, or, alternatively, that peer knowledge is only valuable in certain contexts. Dumbrill and Yee (2019) write that the social work profession is constructed around the idea that social workers are expert knowledge holders and service users are recipients of that knowledge. Based on this understanding of social work, anti-oppressive practice is something social workers "do" and service users "receive", and it is possible that some participants have internalized this hierarchy. Participants in this study take some positive steps 
towards incorporating peer knowledge, although to a lesser degree than peer-run harm reduction organizations, such as VANDU (Jozaghi, 2014; Kerr et al., 2005; Kerr et al., 2006). Therefore, although these actions can be understood as beginning steps towards challenging the marginalization of service users' knowledge within health care and harm reduction, the findings of this study are nonetheless consistent with Dumbrill and Yee's assertion that social service agencies often fall short in centering peer knowledge.

AOP and the criminal justice system. As discussed in the theoretical framework of this MRP, much of the AOP scholarship lacks an examination of the relationship between social work and the criminal justice system. By contrast, participants in this study appeared to center a critical analysis of the criminal justice system, and also seemed critical of harm reduction's role in augmenting its reach. Turning to the AOP scholarship that does analyze the criminal justice system, the actions and opinions described by participants in this study appear to align most with Willison and O'Brien's (2017) calls for criminal justice reform and alternatives to incarceration. Furthermore, both Catherine and Riley spoke in favour of prison abolition; this is the position taken by O'Brien and Ortega (2015), and is in contrast to both Goldingay (2016) and Pollack (2004), who make no such argument in their writings on social work and the carceral system.

The findings of theme three indicate that participants perceive the criminal justice system to have a negative impact in the lives of people who use drugs. Riley spoke of the need to adopt a prison-abolitionist stance and take power away from police, Catherine discussed her belief that incarceration and criminalization increase harms for people who use drugs, and James contended that police and police-like power can escalate conflict. By describing alternative practices to policing, surveillance, and carceral power, participants in this study suggest that a critical stance 
towards the criminal justice system may be an important anti-oppressive strategy within harm reduction.

AOP and anti-colonialism. AOP has been critiqued for its failure to adequately address colonialism (Baskin \& Davey, 2017; Dumbrill \& Yee, 2019; Yee \& Wagner, 2013). Overall, participants in this study did not describe anti-colonialism as a theme within their harm reduction work. The lack of discussion on anti-colonialism, as well as my own methodological failure to center anti-colonialism within recruitment and data collection, reinforce Yee and Wagner's assertion that we must take an explicit anti-colonial stance within anti-oppressive social work. In addition, the absence of findings related to anti-colonialism is at odds with the harm reduction literature, which not only identifies colonialism as a root cause of harm for Indigenous peoples (FNHA, n.d.; Goodman et al., 2017; NYSHN, 2016; Wilson et al., 2016), but also calls on the harm reduction field to do more to incorporate an anti-colonial perspective and support Indigenous political and cultural resurgence (Flicker et al., 2017; NYSHN, 2016; Wilson et al., 2016).

\section{Limitations}

This study has several limitations. As this research was conducted using a small, nonrepresentative sample, the results cannot be generalized; it is possible that other harm reduction workers would approach the topic of this research in different ways. In addition, all participants had social work backgrounds or otherwise worked in social services. It is possible that harm reduction workers from other professions, such as nursing or medicine, would provide different perspectives. While all participants came from social service backgrounds, only one worked in what could be termed a mainstream health care setting; therefore, the results of this study may better reflect anti-oppression practice from a community-level or grassroots perspective. 
Furthermore, all participants in this study were white settlers, and it is possible that Indigenous harm reduction workers or harm reduction workers of colour would bring different perspectives to this research. Finally, this study reflects the views of service providers rather than service users, and it is possible that the latter group would engage with the research topic differently from the former. 


\section{CHAPTER 7. CONCLUSION}

The goal of this MRP has been to come to a better understanding of anti-oppressive practice within the field of harm reduction, by exploring how harm reduction workers in Toronto address structural processes of oppression through their work. This research has taken a critical stance regarding the operation of neoliberalism within the current harm reduction model, in particular neoliberal tenets of personal responsibility and social control. Participants in this study were found to address structural oppressions through harm reduction in the following ways: by conceptualizing harm reduction beyond personal substance use, through peer engagement and mobilization, and by challenging incarceration, policing, and surveillance in the lives of people who use drugs. The practices described by research participants can be collectively interpreted as a politicized approach to harm reduction that resists the individualization of risk, addresses socio-political determinants of harm, and counters the pathologization of people who use drugs. However, the degree to which participants privilege and operationalize peer knowledge appears limited, and participants neglected to discuss anti-colonialism in their work.

\section{Implications}

The results of this study suggest that we must do more to bring people with lived experience, as well as their knowledge, into all areas of social service delivery. Given that so much of our professional powers and identities are derived from the established hierarchy between professional and experiential knowledge (Dumbrill \& Yee, 2019), we must challenge ourselves to work harder at dismantling this hierarchy. I believe this will require an ongoing commitment to critically reflect on the epistemological and ontological assumptions that guide our work. 
This research corroborates scholarship contending that anti-oppressive approaches can too easily ignore colonialism (Baskin \& Davey, 2017; Yee \& Wagner, 2013). Therefore, this study affirms the necessity to center anti-colonialism within social work research and harm reduction practice. To be clear, Indigenous harm reduction workers, activists, and academics are already doing this work (Monchalin, Lesperance, Flicker, Logie, \& Native Youth Sexual Health Network, 2016; NYSHN, 2016). It is therefore the responsibility of settlers, and in particular white settlers like myself, to educate ourselves and teach each other about the impacts of colonization, the role of social work in perpetuating colonialism, and ways that we can support Indigenous resistance and resurgence. As beginning steps, both the AOP scholarship (Dumbrill \& Yee, 2019; Freeman, 2017) and harm reduction literature (NYSHN, 2016) call on social work and harm reduction to more respectfully incorporate Indigenous knowledges and knowledge keepers. Furthermore, the impacts of colonization have been implicated in the current opioid poisoning epidemic (FNHA, n.d.), and scholars have identified the need to include Indigenous sovereignty and land protection within an expanded understanding of harm reduction (Flicker et al., 2017). For these reasons, I believe that settler harm reduction workers like myself must work harder to build trusting relationships with Indigenous land defenders, and to engage in advocacy and activism against pipeline expansion and other colonial projects. As social workers, I believe that we must also call on our unions and professional associations to take explicit stands in opposition to Canada's ongoing attempts to violently eliminate Indigenous resistance, and in support of Indigenous sovereignty movements.

The findings of this study point to a need for more critical research from an AOP perspective on the relationship between the social work profession and the criminal justice system. Participants in this study were highly critical of policing, carceral, and surveillance 
practices, and appeared to consider the criminal justice system to be a structural determinant of harm in the lives of people who use drugs. Although some AOP scholars examine the relationship between our profession and the criminal justice system (Goldingay, 2016; O'Brien \& Ortega, 2015; Pollack, 2004; Willison \& O’Brien, 2017), several key AOP texts do not at all address the impacts of policing or prisons in the lives of service users (Baines, 2017b; Dominelli, 2002; Dumbrill \& Yee, 2019; Morgaine \& Capous-Desyllas, 2015; Parada \& Wehbi, 2017; Wehbi \& Parada, 2017). I find the relative absence of AOP scholarship on this subject to be perplexing. As a queer I distrust the police, given that my community continues to be the target of homophobic police surveillance (McCaskell, 2016; Xtra Spark, 2016). Furthermore, as someone living with HIV, I experience a degree of structural stigma (Gagnon \& Veziné, 2018) and surveillance perpetuated by the continuing criminalization of HIV-positive bodies. Additionally, as a harm reduction worker myself, I have witnessed the violence enacted by various elements of the criminal justice system on the lives of people who use drugs, and therefore share many of the critiques articulated by participants in this study. Based on my positionalities, I believe that anti-oppressive social work practice would be strengthened by a deeper, critical analysis of policing, incarceration, and the role of our profession in relation to the criminal justice system.

A final implication of this research is that, despite the assertions of some authors (Miller, 2001; Roe, 2005; Smith, 2012a), harm reduction practice can clearly be more than behavioural change and biomedical interventions; harm reduction can indeed be political. In making this assertion I do not deny the impact that neoliberal values such as individualism, social control, welfare state retrenchment, and corporate profit-making have on our field of practice. Nor do I suggest that we remain indifferent towards attempts by governments and public health bodies to 
re-package harm reduction in depoliticized terms. However, the harm reduction workers interviewed for this study demonstrate that, even within the current neoliberal reality of social service provision, politicized practice is achievable, and resistance to neoliberalism is possible. It is my critical hope that we continue this resistance in the face of a renewed conservative political reality, in Ontario and elsewhere, which will undoubtedly challenge us in the years ahead. 
RYERSON

UNIVERSITY

\title{
PARTICIPANTS NEEDED FOR RESEARCH IN: ADDRESSING STRUCTURAL OPPRESSIONS THROUGH HARM REDUCTION
}

\author{
Are You:
}

- Working in the field of harm reduction? Or have you worked in harm reduction within the last 3 years (2015-present)?

- Working (or have worked) in the City of Toronto?

- $18+$ years old?

If you answered yes to the above questions you are invited to participate in this study exploring ways that harm reduction workers address racism, patriarchy, ableism, colonization, homophobia, transphobia, and other oppressions that increase harm for people who use substances.

You will be asked to participate in a 1-on-1 interview.

Your participation will involve 1 session 1-1.5 hours in length.

This research is being conducted as part of my studies in the Master of Social Work program. If you are interested in participating in this study or for more information please contact:

Travis Cross

School of Social Work

Email: tjcross@ryerson.ca

This research study has been reviewed and approved by the Ryerson University Research Ethics Board.

\begin{abstract}
Travis Cross
Email: tjcross@ryerson.
\end{abstract}

ca

$$
\text { Travis Cross }
$$

Email: tjcross@ryerson.c

a

\author{
Travis Cross \\ Email: \\ tjcross@ryerson.c
}

a
Travis Cross Email: Email: tjcross@ryerson.ca tjcross@ryerson.ca
Travis Cross Email: tjcross@ryerson.ca 


\section{Appendix B. Recruitment Email Script}

Dear

I am contacting you to see if you would be willing to participate in recruitment for a research study I am doing: Addressing Structural Oppressions through Harm Reduction. The aim of this study is to better understand ways that harm reduction workers address oppressions such as patriarchy, ableism, colonization, racism, homophobia, transphobia, and other oppressions through their work. I am doing this study as a requirement of the Master of Social Work program at Ryerson University, and my research supervisor is Dr. Dawn Onishenko. The Ryerson University Research Ethics Board has approved this research project.

Your participation in helping with recruitment would be completely voluntary. You are under no obligation to participate with recruitment, and if you choose not to participate it will not impact our relationship or your relationship with Ryerson University. If you choose to participate with recruitment, you can participate as much or as little as you wish. You can also stop participating any time, without providing me with notice or a reason for stopping. If you stop participating with recruitment, it would not impact our relationship or your relationship with Ryerson University.

If you choose to participate, you would only be involved in recruitment, and not in other aspects of the research project. I will not ask you to participate in interviews.

If you wish to participate in recruitment, I will provide handbills that you may distribute to people who you believe fit the following criteria:

-Are $18+$ years old.

-Are working in the field of harm reduction, or have worked in harm reduction in the last 3 years (2015-present).

-Are working (or have worked) in the City of Toronto.

If you choose to participate in recruitment, I will not be able to provide reimbursement for your time.

If you wish to participate in recruitment for this research study, please respond to this email to let me know. You may take as much time as you need to respond; however, you are under no obligation to respond at all to this email.

Sincerely,

-Travis Cross 
RYERSON

UNIVERSITY

\title{
PARTICIPANTS NEEDED FOR RESEARCH IN: ADDRESSING STRUCTURAL OPPRESSIONS THROUGH HARM REDUCTION
}

\author{
Are You:
}

- Working in the field of harm reduction? Or have you worked in harm reduction within the last 3 years (2015-present)?

- Working (or have worked) in the City of Toronto?

- $18+$ years old?

If you answered yes to the above questions you are invited to participate in this study exploring ways that harm reduction workers address racism, patriarchy, ableism, colonization, homophobia, transphobia, and other oppressions that increase harm for people who use substances.

You will be asked to participate in a 1-on-1 interview.

Your participation will involve 1 session up to 1.5 hours in length.

This research is being conducted as part of my studies in the Master of Social Work program. If you are interested in participating in this study or for more information please contact:

\section{Travis Cross}

School of Social Work

Email: tjcross@ryerson.ca

Participation is completely voluntary.

The person distributing this handbill has no direct affiliation with this research project.

This research study has been reviewed and approved by the Ryerson University

Research Ethics Board. 


\section{Appendix D. Interview Guide}

\section{Preamble}

Thank you for agreeing to participate in this research project. This interview will take approximately 1-1.5 hours to complete. I want to assure you that your identity will remain confidential, and only my research supervisor and I will have access to the information you provide. Your name will be replaced by a pseudonym and other identifying information (such as name of workplace, names of co-workers, and names of clients) will be removed when I transcribe this interview. This will occur as soon as possible.

Before we begin, I would like your permission to record this interview.

You may ask at any point during this interview to pause the recording and take a break. You may also skip any interview questions that you do not wish to answer, and you do not need to provide a reason for doing so. You may stop the interview and withdraw your consent at any point during this interview, and you do not need to provide a reason for doing so.

Do you have any questions before we begin?

\section{Identity}

1. Would you please describe your identity/social location? For example: gender, race, ethnicity, sexuality, and/or anything else that you feel is important. You can share as much or as little as you are comfortable with.

\section{The Meaning of Harm Reduction}

2. What does the term harm reduction mean to you?

a. Could you describe specific programs or activities that you associate with harm reduction?

b. Could you describe particular values or principles that you associate with harm reduction?

c. What is important to you about practicing from a harm reduction model?

\section{Addressing Oppressions through Harm Reduction}

3. What are your thoughts about issues of oppression (such as white supremacy, colonialism, patriarchy, ableism, capitalism, heteronormativity, cisnormativity, anti-Black racism, Islamophobia, or other oppressions) and the role, if any, they play in harm reduction work?

a. If yes, could you describe what motivates you to feel this way?

b. If no, could you describe what motivates you to feel this way?

c. If yes, could you describe a specific situation in your harm reduction work in which you have tried to address white supremacy, colonialism, patriarchy, ableism, capitalism, heteronormativity, cisnormativity, anti-Black racism, Islamophobia, or an intersection of these processes?

d. If yes, could you describe the ways in which you carried out this work? For example, posing critical questions to staff or managers, casenotes, advocacy, education, self-reflexivity, 
clinical work, advocating to divert a client from prison, naming injustices, listening, activism, or other ways?

e. Do you feel there are any challenges or barriers to addressing oppressions in the harm reduction work you do? If yes, could you describe what those challenges or barriers are?

\section{The Current Opioid Crisis}

4. In your opinion, what is causing the current opioid crisis?

5. How would you describe the impact of the current opioid crisis on your harm reduction work?

6. Could you describe ways that you feel your harm reduction work both adequately or inadequately addresses the current opioid crisis?

\section{Resistance}

7. Do you consider your harm reduction work to be a form of resistance?

a. If yes, what does resistance mean to you?

b. If yes, are there specific socio-political or economic structures, policies, values, or institutions that you are trying to resist?

c. If no, how else would you describe your harm reduction work? 


\section{Appendix E. Research Ethics Board Approval}

REB 2018-075

Project Title: Addressing Structural Oppressions Through Harm Reduction.

\section{Dear Travis Cross,}

The Research Ethics Board has completed the review of your submission. Your research project is now approved for a one year period as of Mar 13, 2018.The approval letter is attached in Adobe Acrobat (PDF) format.

Congratulations and best of luck with the project.

Please note that this approval is for one year only and will expire on March 13, 2019. Shortly before the expiry date a request to complete an annual report will be automatically sent to you. Completion of the annual report takes only a few minutes, enables the collection of information required by federal guidelines and when processed will allow the protocol to remain active for another year.

Please note that REB approval policies require that you adhere strictly to the protocol as last reviewed by the REB. Any modifications must be approved by the Board before they are implemented. Adverse or unexpected events must be reported to the REB as soon as possible with an indication from the Principal Investigator as to how, in the view of the Principal Investigator, these events affect the continuation of the protocol.

Please quote your REB file number (REB 2018-075) on future correspondence.

If you have any questions regarding your submission or the review process, please do not hesitate to get in touch with the Research Ethics Board (contact information below).

No research involving humans shall begin without the prior approval of the Research Ethics Board.

This is part of the permanent record respecting or associated with a research ethics application submitted to Ryerson University.

NOTE: This email account (rebchair@ryerson.ca) is monitored by multiple individuals. If you wish to contact a specific member of the Research Ethics Board, please do so directly.

Yours sincerely,

Zakiya Atcha, MSW

Research Ethics Co-Ordinator 


\section{Appendix F. Consent Form}

RYERSON

UNIVERSITY

\section{Ryerson University Consent Agreement}

You are being invited to participate in a research study. Please read this consent form so that you understand what your participation will involve. Before you consent to participate, please ask any questions to be sure you understand what your participation will involve.

\section{ADDRESSING STRUCTURAL OPPRESSIONS THROUGH HARM REDUCTION}

INVESTIGATORS: This research study is being conducted by Travis Cross, a graduate student in the School of Social Work. This research study is being supervised by Dr. Dawn Onishenko, from the School of Social Work at Ryerson University.

If you have any questions or concerns about the research, please feel free to contact Travis Cross at tjcross@ryerson.ca.

PURPOSE OF THE STUDY: This research study will explore ways that harm reduction workers understand and address structural forms of oppression in their work. Structural forms of oppression include racism, colonization, ableism, patriarchy, homophobia, transphobia, and other forms of oppression.

A maximum of 5 individuals will be recruited to participate in this study.

To be eligible, you must be at least 18 years old; speak English; currently work in the field of harm reduction, or have previously worked in the field of harm reduction within the past 3 years (2015-present); and, your place of employment must be within the City of Toronto.

This research study is being completed as a requirement of the Master of Social Work program at Ryerson University. Results will contribute to a major research paper written by the principle investigator.

WHAT YOU WILL BE ASKED TO DO: If you volunteer to participate in this study, you will be asked to participate in 1 one-on-one interview that will take a maximum of 1.5 hours to complete. This interview will take place in a room within Ryerson University's Student Learning Centre, located at 341 Yonge Street.

Sample Interview Questions:

1. What does harm reduction mean to you? 
2. Could you please describe a situation in which you addressed a form of structural oppression in your harm reduction work?

You will also be given the option to provide any other demographic information that you wish, such as gender, sexuality, race, ethnicity, or other identity markers. However, you are not required to provide any.

Research findings will contribute to a major research paper which will be available online for research participants to read.

POTENTIAL BENEFITS: Potential benefits of this study include the possibility that research participants will feel recognized for the work they undertake; the possibility that research participants will realize, through the research process, previously unexplored ways of addressing structural forms of oppression in their work; and, the possibility that people who read the findings will learn about new or unexplored ways of practicing harm reduction and addressing structural forms of oppression.

I cannot guarantee, however, that you will receive any direct benefits from participating in this study.

\section{WHAT ARE THE POTENTIAL RISKS TO YOU AS A PARTICIPANT:}

Psychological Risk: It is possible that you may become upset or experience emotional discomfort while talking about your work within the field of harm reduction. A list of support services will be provided prior to the start of the interview. All questions are optional; therefore, you may choose not to answer any questions you wish without providing a reason. If I notice that you may be distressed, I will pause the interview and ask if you wish to take a break or end the interview.

Social Risk: There is a low risk that you may become exposed or embarrassed by this research, and you may experience loss of privacy, damage to your reputation, and/or damage to your personal and professional relationships. To decrease these risks, you may choose not to share any information that you feel will identify you in any way. Furthermore, I will remove your name in the data analysis stage and replace it with a code. This code will be used instead of your name in my major research paper. The name of your agency, your job title, names of coworkers, and names of clients will not be included in my major research paper.

CONFIDENTIALITY: This consent form will be stored in a locked filing cabinet; only the principle investigator will have access to it. With your consent, this interview will be recorded. The audio file will be stored in an encrypted file on a password-protected computer that can only be accessed by the principle investigator. Your name will be removed from data during the data analysis phase of research and a pseudonym will be used instead. A key linking your name to the pseudonym will be stored in an encrypted file on a password-protected computer that can only be accessed by the principle investigator. Your name will not be used in the major research paper in which research findings will appear; the pseudonym will be used instead. The name of your workplace, job title, names of co-workers, and names of clients also 
will not appear in the major research paper. You will not have the option to have your real name listed in the major research paper.

Research data will be retained for 12 months after final submission of the major research paper, after which time it will be destroyed. Electronic files will be deleted and this consent form will be shredded.

Research data may be shared with the research supervisor, Dr. Dawn Onishenko. No other individuals will have access to research data.

If it becomes apparent that an individual has been harmed, or will be harmed, the principle investigator is required to report that information to authorities.

The interview will be audio-recorded and stored in an encrypted file on a passwordprotected computer. Audio recordings will be transcribed at the earliest possible time and destroyed once transcriptions have been verified. All identifying information will be removed during transcription, to be replaced with pseudonyms where necessary. The principle investigator will have access to raw and transcribed recordings, and may share recordings with the research supervisor, Dr. Dawn Onishenko. Transcriptions will be destroyed 12 months after final submission of the major research paper. You may review the transcription of your interview by contacting the principle investigator through email.

COSTS TO PARTICIPATION: You may have to pay for transit, parking, or child care in order to participate in this research project. Reimbursement will not be possible.

By agreeing to participate in this research, you are not giving up or waiving any legal right in the event that you are harmed during the research.

VOLUNTARY PARTICIPATION AND WITHDRAWAL: Participation in this study is completely voluntary. You can choose whether to be in this study or not. If any question makes you uncomfortable, you can skip that question. You may stop participating at any time. If you choose to stop participating, you may also choose to not have your data included in the study. Please inform the principle investigator by email by May 312018 if you decide that you do not wish to have your data to be included in this study; it will be destroyed within 48 hours of receipt of your request. Your choice of whether or not to participate will not influence your future relations with Ryerson University or the investigators involved in the research.

QUESTIONS ABOUT THE STUDY: If you have any questions about the research now, please ask. If you have questions later about the research, you may contact:

Travis Cross, primary investigator. Email: tjcross@ryerson.ca

Dr. Dawn Onishenko, research supervisor. Email: donishenko@ryerson.ca Phone: 416979-5000 ext. 4792

This study has been reviewed by the Ryerson University Research Ethics Board. If you have questions regarding your rights as a participant in this study please contact: 
Research Ethics Board

c/o Office of the Vice President, Research and Innovation

Ryerson University

350 Victoria Street

Toronto, ON M5B 2K3

416-979-5042

rebchair@ryerson.ca

\section{ADDRESSING STRUCTURAL OPPRESSIONS THROUGH HARM REDUCTION}

\section{CONFIRMATION OF AGREEMENT:}

Your signature below indicates that you have read the information in this agreement and have had a chance to ask any questions you have about the study.

Your signature also indicates that you agree to participate in the study and have been told that you can change your mind and withdraw your consent to participate at any time.

You have been given a copy of this agreement.

You have been told that by signing this consent agreement you are not giving up any of your legal rights.

Name of Participant (please print)

Signature of Participant

Date

Age of Participant

I agree to be audio-recorded for the purposes of this study. I understand how these recordings will be stored and destroyed.

Signature of Participant

Date 


\section{References}

Ayo, N. (2012). Understanding health promotion in a neoliberal climate and the making of health conscious citizens. Critical Public Health, 22(1), 99-105.

doi:10.1080/09581596.2010.520692

Baines, D. (2017a). Anti-oppressive practice: Roots, theory, tensions. In D. Baines (Ed.), Doing anti-oppressive practice: Social justice social work (3rd ed., pp. 2-29). Halifax, NS: Fernwood.

Baines, D. (2017b). Doing anti-oppressive practice: Social justice social work (3rd ed.) Halifax, NS: Fernwood.

Bardwell, G., Strike, C., Altenberg, J., Barnaby, L., \& Kerr, T. (2019). Implementation contexts and the impact of policing on access to supervised consumption services in Toronto, Canada: A qualitative comparative analysis. Harm Reduction Journal, 16(1), 1-30. doi:10.1186/s12954-019-0302-X

Barnoff, L., \& Moffatt, K. (2007). Contradictory tensions in anti-oppression practice in feminist social services. Affilia, 22(1), 56-70. doi:10.1177/0886109906295772

Barnoff, L., Abdillahi, I., \& Jordan, B. (2017). Building anti-oppressive organizations: Thoughts from a multi-dimensionally informed journey. In H. Parada \& S. Wehbi (Eds.), Reimagining anti-oppression social work research, (pp. 137-152). Toronto, ON: Canadian Scholars' Press.

Baskin, C. (2016). Strong helpers' teachings: The value of Indigenous knowledges in the helping professions (2nd ed.). Toronto, ON: Canadian Scholars' Press. 
Baskin, C. \& Davey, C. (2017). Parallel Pathways to Decolonization: Critical and Indigenous Social Work. In H. Parada \& S. Wehbi (Eds.), Reimagining anti-oppression social work research, (pp. 3-16). Toronto, ON: Canadian Scholars' Press.

Bourgois, P., Prince, B., \& Moss, A. (2004). The everyday violence of hepatitis C among young women who inject drugs in San Francisco. Human Organization, 63(3), 253-264. doi:10.17730/humo.63.3.h1phxbhrb7m4mlv0

Boyd, J., Collins, A. B., Mayer, S., Maher, L., Kerr, T., \& McNeil, R. (2018). Gendered violence and overdose prevention sites: A rapid ethnographic study during an overdose epidemic in Vancouver, Canada. Addiction, 113(12), 2261-2270. doi:10.1111/add.14417

Brinkmann, S., \& Kvale, S. (2015). InterViews: Learning the craft of qualitative research interviewing (Third ed.). Thousand Oaks, CA: Sage Publications.

Brown, C. (2012). Anti-oppression through a postmodern lens: Dismantling the master's conceptual tools in discursive social work practice. Critical Social Work, 13(1), 34-65. Retrieved from http://www1.uwindsor.ca/criticalsocialwork/

Burstow, B. (2003). Toward a radical understanding of trauma and trauma work. Violence Against Women, 9(11), 1293-1317. doi:10.1177/1077801203255555

Butler, J. \& Athanasiou, A. (2013). Dispossession: The performative in the political. Cambridge: Polity.

Canadian AIDS Society (2015). Peerology: A guide by and for people who use drugs on how to get involved. Retrieved from http://www.cdnaids.ca/resources/populations/people-usedrugs/

CMAJ (2018, January 22). New hope for unsanctioned safe injection site. CMAJ News. Retrieved from https://cmajnews.com. 
Cooper, H. L. F., Linton, S., Kelley, M. E., Ross, Z., Wolfe, M. E., Chen, Y., . . National HIV Behavioral Surveillance Study Group. (2016). Racialized risk environments in a large sample of people who inject drugs in the United States. International Journal of Drug Policy, 27, 43-55. doi:10.1016/j.drugpo.2015.07.015

Creswell, J. W. \& Poth, C. N. (2018). Qualitative inquiry and research design: Choosing among five approaches ( $4^{\text {th }}$ ed.). Thousand Oaks, CA: Sage Publications.

Csiernick, R., Rowe, W. S., \& Watkin, J. (2017). Prevention as controversy: Harm reduction. In R. Csiernick \& W. S. Rowe (Eds.), Responding to the oppression of addiction: Canadian social work perspectives (3rd ed., pp. 28-47). Toronto, ON: Canadian Scholars' Press.

Dodds, C. (2002). Messages of responsibility: HIV/AIDS prevention materials in England. Health, 6(2), 139-171. doi:10.1177/136345930200600202

Dollar, C. B. (2018). Criminalization and drug "wars" or medicalization and health "epidemics": How race, class, and neoliberal politics influence drug laws. Critical Criminology, 1-23. doi:10.1007/s10612-018-9398-7

Dominelli, L. (2002). Anti-oppressive social work theory and practice. Basingstoke: Palgrave Macmillan.

Duggan, L. (2003). The twilight of equality? Neoliberalism, cultural politics, and the attack on democracy. Boston, MA: Beacon Press.

Dumbrill, G. C., \& Yee, J. Y. (2019). Anti-oppressive social work: Ways of knowing, talking, and doing. Don Mills, ON: Oxford University Press. 
Elliott, D. (2014). Debating safe injecting sites in Vancouver's inner city: Advocacy, conservatism and neoliberalism. Contemporary Drug Problems, 41(1), 5-40. doi:10.1177/009145091404100102

Faulkner-Gurstein, R. (2017). The social logic of naloxone: Peer administration, harm reduction, and the transformation of social policy. Social Science \& Medicine, 180, 20-27. doi:10.1016/j.socscimed.2017.03.013

Finlay, L. (2008). A dance between the reduction and reflexivity: Explicating the "phenomenological psychological attitude". Journal of Phenomenological Psychology, 39(1), 1-32. doi:10.1163/156916208X311601

Finlay, L. (2009). Debating phenomenological research methods. Phenomenology \& Practice, 3 (1), 6-25. Retrieved from https://journals.library.ualberta.ca/pandpr/index.php/pandpr First Nations Health Authority (n.d.). Overdose data and First Nations in BC: Preliminary findings. Retrieved from http://www.fnha.ca/newsContent/Documents/FNHA_OverdoseDataAndFirstNationsInBC_ PreliminaryFindings_FinalWeb.pdf

First Nations Health Authority (2019). First Nations opioid overdose deaths rise in 2018. Retrieved from http://www.fnha.ca/newsContent/Documents/FNHA-First-Nations-OpioidOverdose-Deaths-Rise-in-2018-News-Release.pdf

Fischer, B., Turnbull, S., Poland, B., \& Haydon, E. (2004). Drug use, risk and urban order: Examining supervised injection sites (SISs) as 'governmentality'. International Journal of Drug Policy, 15(5), 357-365. doi:10.1016/j.drugpo.2004.04.002

Flicker, S., Wilson, C., Monchalin, R., Oliver, V., Prentice, T., Jackson, R., . . Native Youth Sexual Health Network. (2017). "Stay strong, stay sexy, stay Native": Storying Indigenous 
youth HIV prevention activism. Action Research, 0(0), 1-21. doi:10.1177/1476750317721302

Flood, A. (2010). Understanding phenomenology. Nurse Researcher, 17(2), 7-15. doi: 10.7748/nr2010.01.17.2.7.c7457

Foth, T., O'Byrne, P., \& Holmes, D. (2016). Health prevention in the era of biosocieties: A critical analysis of the 'seek-and-treat' paradigm in HIV/AIDS prevention. Nursing Inquiry, 23(2), 99-108. doi:10.1111/nin.12114

Foucault, M. (2008). The birth of biopolitics: Lectures at the Collège de France, 1978-79. Basingstoke: Palgrave Macmillan.

Fraser, S. (2004). It's your life!': Injecting drug users, individual responsibility and hepatitis C prevention. Health, 8(2), 199-221. doi:10.1177/1363459304041070

Freeman, B. (2017). Soup days and decolonization: Indigenous pathways to anti-oppressive practice. In D. Baines (Ed.), Doing anti-oppressive practice: Social justice social work (3rd ed., pp. 105-121). Halifax, NS: Fernwood.

Friedman, S. R., de Jong, W., Rossi, D., Touze, G., Rockwell, R., Des Jarlais, D. C., \& Elovich, R. (2007). Harm reduction theory: Users culture, micro-social indigenous harm reduction, and the self-organization and outside-organizing of users' groups. International Journal of Drug Policy, 18(2), 107-117. doi:10.1016/j.drugpo.2006.11.006

Gagnon M. \& Veziné, C. (2018). HIV criminalization as "risk management": On the importance of structural stigma. In M. Orsini, M. Gagnon, \& S. Hindmarch (Eds.), Seeing red: HIV/AIDS and public policy in Canada (pp. 55-78). Toronto, ON: University of Toronto Press. 
Giwa, S., \& Greensmith, C. (2012). Race relations and racism in the LGBTQ community of Toronto: Perceptions of gay and queer social service providers of color. Journal of Homosexuality, 59(2), 149-185. doi:10.1080/00918369.2012.648877

Goodman, A., Fleming, K., Markwick, N., Morrison, T., Lagimodiere, L., Kerr, T., \& Western Aboriginal Harm Reduction Society. (2017). "They treated me like crap and I know it was because I was Native": The healthcare experiences of Aboriginal peoples living in Vancouver's inner city. Social Science \& Medicine 178(2017), 87-94. doi:10.1016/j.socscimed.2017.01.053

Goldingay, S. (2016). Building relationships and effecting change: Critical social work practice in prison settings. In B. Pease \& S. Nipperess (Eds.), Doing critical social work: Transformative practices for social justice (pp. 163-175). Crows Nest, NSW, Australia: Allen \& Unwin.

Gordon, T. (2006). Neoliberalism, racism, and the war on drugs in Canada. Social Justice, 33(1), 59-78. Retrieved from http://www.socialjusticejournal.org/

Government of Canada (2018). Harm Reduction: Canadian drugs and substances strategy. Retrieved from https://www.canada.ca/en/health-canada/services/substance-use/canadiandrugs-substances-strategy/harm-reduction.html

Government of Canada (2019). National report: Apparent opioid-related deaths in Canada. Retrieved from https://health-infobase.canada.ca/datalab/national-surveillance-opioidmortality.html\#keyFindings

Greer, A. M., Luchenski, S. A., Amlani, A. A., Lacroix, K., Burmeister, C., \& Buxton, J. A. (2016). Peer engagement in harm reduction strategies and services: A critical case study 
and evaluation framework from British Columbia, Canada. BMC Public Health, 16(1), 452-9. doi:10.1186/s12889-016-3136-4

Gupta, G. R., Parkhurst, J. O., Ogden, J. A., Aggleton, P., \& Mahal, A. (2008). HIV prevention 4: Structural approaches to HIV prevention. The Lancet, 372(9640), 764-775. doi: $10.1016 / \mathrm{S} 01406736(08) 60887-9$

Harm Reduction International (2019). What is harm reduction? Retrieved from https://www.hri.global/what-is-harm-reduction

Hopkins, R. M., Regehr, G., \& Pratt, D. D. (2017). A framework for negotiating positionality in phenomenological research. Medical Teacher, 39(1), 20-25.

doi:10.1080/0142159X.2017.1245854

Hyshka, E., Anderson-Baron, J., Karekezi, K., Belle-Isle, L., Elliott, R., Pauly, B., . . Wild, T. C. (2017). Harm reduction in name, but not substance: A comparative analysis of current Canadian provincial and territorial policy frameworks. Harm Reduction Journal, 14(1), 114. doi:10.1186/s12954-017-0177-7

Hyshka, E., Anderson-Baron, J., Pugh, A., Belle-Isle, L., Hathaway, A., Pauly, B., . . Wild, T. C. (2019). Principles, practice, and policy vacuums: Policy actor views on provincial/territorial harm reduction policy in Canada. The International Journal on Drug Policy. doi:10.1016/j.drugpo.2018.12.014

Irvine, M. A., Kuo, M., Buxton, J. A., Balshaw, R., Otterstatter, M., Macdougall, L., . . Gilbert, M. (2019). Modelling the combined impact of interventions in averting deaths during a synthetic-opioid overdose epidemic. Addiction, 114(9), 1602-1613. doi:10.1111/add.14664 
Jiao, S. (2019). Harm reduction: Philosophical drivers of conceptual tensions and ways forward. Nursing Inquiry, 26(2), 1-6. doi:10.1111/nin.12286

Jozaghi, E. (2014). The role of drug users' advocacy group in changing the dynamics of life in the Downtown Eastside of Vancouver, Canada. Journal of Substance Use, 19(1-2), 213218. doi:10.3109/14659891.2013.775608

Karabanow, J. (2004). Making organizations work: Exploring characteristics of anti-oppressive organizational structures in street youth shelters. Journal of Social Work, 4(1), 47-60. doi: $10.1177 / 1468017304042420$

Kerr, T., Oleson, M., Tyndall, M. W., Montaner, J., \& Wood, E. (2005). A description of a peerrun supervised injection site for injection drug users. Journal of Urban Health, 82(2), 267275. doi:10.1093/jurban/jti050

Kerr, T., Small, W., Peeace, W., Douglas, D., Pierre, A., \& Wood, E. (2006). Harm reduction by a "user-run" organization: A case study of the Vancouver Area Network of Drug Users. International Journal of Drug Policy, 17(2), 61-69. doi:10.1016/j.drugpo.2006.01.003

Khenti, A. (2014). The Canadian war on drugs: Structural violence and unequal treatment of Black Canadians. International Journal of Drug Policy, 25(2), 190-195. doi:10.1016/j.drugpo.2013.12.001

Klein, A. (2015). Criminal law and the counter-hegemonic potential of harm reduction. Dalhousie Law Journal, 38(2), 447-471. Retrieved from https://digitalcommons.schulichlaw.dal.ca/dlj/

Krüsi, A., McNeil, R., Moore, D., \& Small, W. (2017). 'Because I've been extremely careful': HIV seroconversion, responsibility, citizenship and the neo-liberal drug-using subject. Health, Risk \& Society, 19(1-2), 58-73. doi:10.1080/13698575.2016.1245850 
Langdridge, D. (2008). Phenomenology and critical social psychology: Directions and debates in theory and research. Social and Personality Psychology Compass, 2(3), 1126-1142. doi:10.1111/j.1751-9004.2008.00114.x

Larson, G. (2008). Anti-oppressive practice in mental health. Journal of Progressive Human Services, 19(1), 39-54. doi:10.1080/10428230802070223

Lee, E. O. J. and Ferrer, I. (2014). Examining social work as a Canadian settler colonial project: Colonial continuities of circles of reform, civilization, and in/visibility. Journal of Critical Anti-Oppressive Social Inquiry, 1(1), 1-20. Retrieved from https://caos.library.ryerson.ca

Leece, P., Gassanov, M., Hopkins, S., Marshall, C., Millson, P., \& Shahin, R. (2016). Process evaluation of the prevent overdose in toronto (POINT) program. Canadian Journal of Public Health/ Revue Canadienne De Santé Publique, 107(3), e224-e230. doi:10.17269/CJPH.107.5480

Lemke, T. (2001). 'The birth of bio-politics': Michel Foucault's lecture at the Collège de France on neo-liberal governmentality. Economy and Society, 30(2), 190-207. doi:10.1080/03085140120042271

Marshall, S. G. (2015). Canadian drug policy and the reproduction of Indigenous inequities. International Indigenous Policy Journal, 6(1), 1-19. doi:10.18584/iipj.2015.6.1.7

McCaskell, T. (2016). Queer progress: From homophobia to homonationalism. Toronto, ON: Between the Lines.

McLean, K. (2015). From responsible users to recalcitrant dope fiends: Mapping modes of engagement with harm reduction. Addiction Research \& Theory, 23(6), 490-498. doi:10.3109/16066359.2015.1040001 
McLean, K. (2016). "There's nothing here": Deindustrialization as risk environment for overdose. The International Journal on Drug Policy, 29, 19-26. doi: 10.1016/j.drugpo.2016.01.009

Miller, P. G. (2001). A critical review of the harm minimization ideology in Australia. Critical Public Health, 11(2), 167-178. doi:10.1080/09581590110039865

Ministry of Health and Long-term Care (2018). Substance use prevention and harm reduction guideline, 2018. Retrieved from http://www.health.gov.on.ca/en/pro/programs/publichealth/oph_standards/docs/protocols_ guidelines/Substance_Use_Prevention_and_Harm_Reduction_Guideline_2018_en.pdf

Monchalin, R., Lesperance, A., Flicker, S., Logie, C., \& Native Youth Sexual Health Network. (2016). Sexy health carnival on the powwow trail: HIV prevention by and for Indigenous youth. International Journal of Indigenous Health, 11(1), 159.

doi:10.18357/ijih111201616011

Moore, D. (2004). Governing street-based injecting drug users: A critique of heroin overdose prevention in Australia. Social Science \& Medicine, 59(7), 1547-1557. doi:10.1016/j.socscimed.2004.01.029

Moore, D., \& Fraser, S. (2006). Putting at risk what we know: Reflecting on the drug-using subject in harm reduction and its political implications. Social Science \& Medicine, 62(12), 3035-3047. doi:10.1016/j.socscimed.2005.11.067

Moosa-Mitha, M. (2015). Situating anti-oppressive theories within critical and differencecentered perspectives. In S. Strega \& L. Brown (Eds.), Research as resistance: revisiting critical, Indigenous, and anti-oppressive approaches ( $2^{\text {nd }} \mathrm{ed}$, pp. 65-95). Toronto, ON: Canadian Scholars' Press. 
Morgaine, K., \& Capous-Desyllas, M. (2015). Anti-oppressive social work practice: Putting theory into action. Thousand Oaks, CA: Sage Publications.

Mullaly, B. (2007). The new structural social work (3rd ed.) Toronto, ON: Oxford University Press.

Narayan, U. (1988). Working together across difference: Some considerations on emotions and political practice. Hypatia, 3(2), 31-47. doi:10.1111/j.1527-2001.1988.tb00067.x

Native Youth Sexual Health Network (2016). Indigenizing harm reduction: Moving beyond the four-pillar model. Visions: BC's Mental Health and Addictions Journal, 11(4), 36-39. Retrieved from http://www.heretohelp.bc.ca/sites/default/files/visions-indigenous-peoplevol11.pdf

O’Brien, P., \& Ortega, D. M. (2015). Feminist transformation deconstructing prisons and reconstructing justice with criminalized women. Affilia, 30(2), 141-144. doi:10.1177/0886109915575667

Parada, H., \& Wehbi, S. (2017). Reimagining anti-oppression social work research. Toronto, ON: Canadian Scholars' Press.

Pauly, B. (2008). Harm reduction through a social justice lens. International Journal of Drug Policy, 19(1), 4-10. doi:10.1016/j.drugpo.2007.11.005

Pauly, B., McCall, J., Browne, A. J., Parker, J., \& Mollison, A. (2015). Toward cultural safety: Nurse and patient perceptions of illicit substance use in a hospitalized setting. Advances in Nursing Science, 38(2), 121-135. doi:10.1097/ANS.0000000000000070

Pollack, S. (2004). Anti-oppressive social work practice with women in prison: Discursive reconstructions and alternative practices. The British Journal of Social Work, 34(5), 693707. doi:10.1093/bjsw/bch085 
Pollack, S., \& Rossiter, A. (2010). Neoliberalism and the entrepreneurial subject: Implications for feminism and social work. Canadian Social Work Review / Revue Canadienne De Service Social, 27(2), 155-169. Retrieved from https://caswe-acfts.ca/cswr-journal/

Pon, G., Gosine, K., \& Phillips, D. (2011). Immediate response: Addressing anti-Native and antiBlack racism in child welfare. International Journal of Child, Youth and Family Studies, 2(3\&4), 385-409. doi:10.18357/ijcyfs23/420117763

Preston, S. \& Redgrift, L. (2017). Phenomenology as social work inquiry: Parallels and divergences with anti-oppressive research. In H. Parada \& S. Wehbi (Eds.), Reimagining anti-oppression social work research, (pp. 87-98). Toronto, ON: Canadian Scholars' Press.

Reynolds, V. (2016). Hate kills: A social justice response to “suicide”. In J. White, I. Marsh, M. J. Kral, \& J. Morris (Eds.), Critical suicidology: Transforming suicide research and prevention for the 21st century. Vancouver, BC: UBC Press.

Rhodes, T. (2009). Risk environments and drug harms: A social science for harm reduction approach. International Journal of Drug Policy, 20(3), 193-201.

doi:10.1016/j.drugpo.2008.10.003

Roe, G. (2005). Harm reduction as paradigm: Is better than bad good enough? The origins of harm reduction. Critical Public Health, 15(3), 243-250. doi:10.1080/09581590500372188

Ross, M. (2017). Social work activism within neoliberalism: A big tent approach? In D. Baines (Ed.), Doing anti-oppressive practice: Social justice social work (3rd ed., pp. 272-288). Halifax, NS: Fernwood.

Saldaña, J. (2009). The coding manual for qualitative researchers. Thousand Oaks, CA: Sage Publications. 
Sinclair, R. (2004). Aboriginal social work education in Canada: Decolonizing pedagogy for the seventh generation. First Peoples Child and Family Review, 1(1), 49-61. Retrieved from https://fncaringsociety.com/first-peoples-child-family-review

Smith, C. B. R. (2012a). Harm reduction as anarchist practice: A user's guide to capitalism and addiction in north america. Critical Public Health, 22(2), 209-221. doi:10.1080/09581596.2011.611487

Smith, J. A. (2004). Reflecting on the development of interpretative phenomenological analysis and its contribution to qualitative research in psychology. Qualitative Research in Psychology, 1(1), 39. doi:10.1191/1478088704qp004oa

Smith, J. A., Larkin, M. H., \& Flowers, P. (2009). Interpretative phenomenological analysis: Theory, method and research. Thousand Oaks, CA: Sage Publications.

Smith, J. A. (2017). Interpretative phenomenological analysis: Getting at lived experience. The Journal of Positive Psychology, 12(3), 303-304. doi:10.1080/17439760.2016.1262622

Souleymanov, R., \& Allman, D. (2016). Articulating connections between the harm-reduction paradigm and the marginalisation of people who use illicit drugs. British Journal of Social Work, 46(5), 1429-1445. doi:10.1093/bjsw/bcv067

Strega, S. (2015). The view from the poststructural margins: epistemology and methodology reconsidered. In S. Strega \& L. Brown (Eds.), Research as resistance: Revisiting critical, Indigenous, and anti-Oppressive approaches ( $2^{\text {nd }}$ ed., pp. 119-152). Toronto, ON: Canadian Scholars' Press.

Strier, R., \& Binyamin, S. (2010). Developing anti-oppressive services for the poor: A theoretical and organisational rationale. The British Journal of Social Work, 40(6), 19081926. doi:10.1093/bjsw/bcp122 
Stimson, G. V. (2007). "Harm reduction-coming of age": A local movement with global impact. The International Journal of Drug Policy, 18(2), 67-69. doi: 10.1016/j.drugpo.2006.12.012 Thomann, M. (2018). 'On December 1, 2015, sex changes. Forever': Pre-exposure prophylaxis and the pharmaceuticalisation of the neoliberal sexual subject. Global Public Health, 13(8), 997-1006. doi:10.1080/17441692.2018.1427275

Thomas, R. \& Green, J. (2007). A way of life: Indigenous perspectives on anti oppressive living. First Peoples Child and Family Review, 3(1), 91-104. Retrieved from https://fncaringsociety.com/first-peoples-child-family-review

Tuohy, D., Cooney, A., Dowling, M., Murphy, K., \& Sixsmith, J. (2013). An overview of interpretive phenomenology as a research methodology. Nurse Researcher, 20(6), 17-20. doi: $10.7748 / \mathrm{nr} 2013.07 .20 .6 .17 . \mathrm{e} 315$

Wacquant, L. (2001). The penalisation of poverty and the rise of neo-liberalism. European Journal on Criminal Policy and Research, 9(4), 401-412. doi:10.1023/A:1013147404519

Wacquant, L. (2009). Punishing the poor: The neoliberal government of social insecurity. Durham, NC: Duke University Press.

Wehbi, S., \& Parada, H. (2017). Reimagining anti-oppression social work practice. Toronto, ON: Canadian Scholars' Press.

Willison, J. S., \& O’Brien, P. (2017). A feminist call for transforming the criminal justice system. Affilia, 32(1), 37-49. doi:10.1177/0886109916658080

Wilson, C., Oliver, V., Flicker, S., Prentice, T., Jackson, R., Larkin, J., . . Mitchel, C. (2016). 'Culture' as HIV prevention: Indigenous youth speak up. Gateways: International Journal of Community Research and Engagement, 9(1), 74-88. doi:10.5130/ijcre.v9i1.4802 
Wojnar, D. M., \& Swanson, K. M. (2007). Phenomenology: An exploration. Journal of Holistic Nursing, 25(3), 172-180. doi:10.1177/0898010106295172

Xtra Spark (2016, November 28). Project Marie is the latest chapter in Toronto police's long history of targeting queers. Xtra. Retrieved from https:/www.dailyxtra.com/

Yee, J. Y., \& Wagner, A. E. (2013). Is anti-oppression teaching in Canadian social work classrooms a form of neo-liberalism? Social Work Education, 32(3), 331-348. doi:10.1080/02615479.2012.672557

Young, I. M. (1990). “Five Faces of Oppression," justice and the politics of difference. Princeton, NJ: Princeton University Press. 